\title{
The controls on earthquake ground motion in foreland-basin settings: The effects of basin and source geometry
}

\author{
Aisling O'Kane ${ }^{1 *}$ and Alex Copley ${ }^{1}$ \\ ${ }^{1}$ COMET, Bullard Laboratories, Department of Earth Sciences, University of Cambridge, UK \\ *amo49@cam.ac.uk \\ Accepted XX/XX/XXXX; Received XX/XX/XXXX; In original form 28/08/2020
}

\section{Summary}

Rapid urban growth has led to large population densities in foreland basin regions, and therefore a rapid increase in the number of people exposed to hazard from earthquakes in the adjacent mountain ranges. It is well known that earthquake-induced ground shaking is amplified in sedimentary basins. However, questions remain regarding the main controls on this effect. It is, therefore, crucial to identify the main controls on earthquake shaking in foreland basins as a step towards mitigating the earthquake risk posed to these regions. We model seismic-wave propagation from range-front thrust-faulting earthquakes in a foreland-basin setting. The basin geometry (depth and width) and source characteristics (fault dip and source-to-basin distance) were varied, and the resultant ground motion was calculated. We find that the source depth determines the amount of near-source ground shaking and the basin structure controls the propagation of this energy into the foreland basin. Of particular importance is the relative length scales of the basin depth and dominant seismic wavelength (controlled by the source characteristics), as this controls the amount of dispersion of surface-wave energy, and so the amplitude and duration of ground motion. The maximum ground motions occur when the basin depth matches the dominant wavelength set by the source. Basins that are shallow compared with the dominant wavelength result in low-amplitude and long-duration dispersed waveforms. However, the basin structure has a smaller effect on the ground shaking than the source depth and geometry, highlighting the need for understanding the depth distribution and dip angles of earthquakes when assessing earthquake hazard in foreland-basin settings.

\section{Key Words:}

- Earthquake ground motions, Wave propagation, Earthquake hazards, Continental tectonics: compressional, Seismicity and tectonics 


\section{Introduction}

A foreland basin is typically a wedge-shaped, sedimentary basin that forms adjacent to a mountain front in a fold-thrust belt, in response to lithospheric flexure during orogenesis [e.g. DeCelles and Giles, 1996]. This work will primarily focus on foreland basins in continental collisional settings, as earthquakes within the continental interiors have a long record of producing catastrophic damage and loss of life [e.g. England and Jackson, 2011].

Foreland basins pose several hazards to people who reside in cities built upon them. Due to rapid urban growth, $\sim 56 \%$ of the world's population now lives in urban areas, with cities and even megacities (e.g. Delhi; Population $>28$ million) existing within some foreland-basin settings [Cox, 2019] (see Fig. 1). These cities are built on thick layers of sediment [Burbank et al., 1996; Campbell et al., 2013; Gavillot et al., 2016; Grützner et al., 2017], located on or near active faults [Tapponnier and Molnar, 1979; Thompson et al., 2002; England and Jackson, 2011; Abdrakhmatov et al., 2016] and have a history of large destructive earthquakes [Bilham, 2004; Lavé et al., 2005; Pathier et al., 2006; England and Jackson, 2011; Lay et al., 2017]. Fig. 1 illustrates the location of known faults, foreland and intermontane basins, and past seismicity within Central Asia. When compared with the inset map showing population density [CIESIN, 2016], it can be seen that areas with high population densities often overlay basins in seismically active regions, or occur along range fronts. It is well established that ground shaking due to earthquakes is amplified in sedimentary basins [Bard and Bouchon, 1985; Sanchez, 1987; Rial et al., 1992; Olsen et al., 2003; LeBrun et al., 2002; Aagaard et al., 2008; Lozano et al., 2009; Taborda and Bielak, 2013; Galetzka et al., 2015; Meza-Fajardo et al., 2016; Bowden and Tsai, 2017; Rupakhety et al., 2017]. However, questions remain as to the relative importance of the factors that control this effect, which is a mixture of source characteristics and the wave-propagation effects. In this paper we investigate the controls on earthquake shaking in foreland basins, to better understand the seismic hazard that these regions pose to their inhabitants.

There are several methods for modelling earthquake ground shaking, each with distinct benefits and limitations. Ground Motion Prediction Equations (GMPEs) (also commonly known as Ground Motion Models (GMMs)) are used to estimate the expected ground shaking for a given area based on earthquake magnitude and mechanism, source-to-site distance and local geological conditions [e.g. Douglas, 2019, and references therein]. GMPEs are empirical fits to specific observations and use regression analysis between recorded ground motion and an intensity measure like damage statistics [Wu et al., 2003] or Modified Mercalli Intensity [Wald et al., 1999]. This technique is particularly useful 
for real-time applications such as performing earthquake-loss assessments for emergency response and disaster management purposes in the immediate aftermath of an earthquake [Wu et al., 2003]. However, most GMPEs do not account for spatial variations in path and/or site effects, which are known to significantly affect ground motions [Lastrico et al., 1972; Drake, 1980; Bard and Bouchon, 1985; Sanchez, 1987; Kawase and Aki, 1989; Olsen and Schuster, 1995; Joyner, 2000; Day et al., 2008; Frankel et al., 2009; LeBrun et al., 2002; Taborda and Bielak, 2013; Bhattarai et al., 2015; Bowden and Tsai, 2017; Rajaure et al., 2017; Rodgers et al., 2018; Wirth et al., 2019]. Furthermore, only limited regions have the required density of observations to allow GMPEs to be derived, leading to location bias in the resulting equations [Abrahamson and Silva, 1997; Sadigh et al., 1997; Campbell and Bozorgnia, 2008; Boore and Atkinson, 2008; Chiou and Youngs, 2008; Idriss, 2008; Power et al., 2008; Campbell et al., 2009; Gülerce et al., 2013]. Therefore, there is a reason for considering other techniques in parallel, which allow us to investigate the effects of lateral heterogeneity in the crust on the duration and intensity of ground motion.

Modelling of seismic-wave propagation is an alternative method for investigating seismic ground motion, which allows for a variety of geological structures to be incorporated into the models. This method is becoming more frequently used as computational resources have improved and more accurate 3-D velocity models of the Earth's structure have been produced [Rodgers et al., 2018]. Many studies have applied these methods to specific locations, such as in Southern California [Olsen, 2000; Graves and Pitarka, 2004; Olsen et al., 2003; Aagaard et al., 2008; Day et al., 2008; Graves et al., 2008; Harmsen et al., 2008; Aagaard et al., 2010; Bielak et al., 2010; Hartzell et al., 2010; Taborda and Bielak, 2013; Graves and Pitarka, 2016; Rodgers et al., 2018, 2019; Rodgers, 2019], Utah [Olsen and Schuster, 1995], Cascadia [Frankel et al., 2009; Wirth et al., 2019], Grenoble [Chaljub et al., 2005, 2010] and western Japan [Asano et al., 2016]. In this paper, we take a slightly different approach and perform calculations using an idealised geological structure, which can then be applied to a range of locations.

This study aims to identify the main controls of earthquake shaking in foreland basins on a regional scale and over a broad range of frequencies. Rather than model a specific basin, we aim to examine ground motion in a generic foreland-basin geometry. We intend to establish the main source and structural controls on the ground motion and therefore deduce underlying principles that can then be applied to a range of specific locations. 


\section{Methodology}

SW4 (Seismic Waves, 4th Order) is a finite difference code [Petersson and Sjögreen, 2017a] that we have used to simulate seismic-wave propagation through a foreland-basin setting from a thrust-faulting earthquake along the range front of a mountain belt. The code solves the elastic and viscoelastic wave equations and is fourth-order accurate in time and space [Petersson and Sjögreen, 2012; Sjögreen and Petersson, 2012; Petersson and Sjögreen, 2014, 2015, 2017b]. SW4's capabilities made it an appropriate tool for use in this study, especially its ability to use a damping layer on all model boundaries (except the surface) to reduce artificial reflections from far-field boundaries [Petersson and Sjögreen, 2012, 2014, 2015, 2017b]. SW4 has already been applied to investigate seismic ground motions and has successfully reproduced ground motions consistent with GMPEs in the areas where they are defined [Imperatori and Gallovič, 2017; Rodgers et al., 2018, 2019]. Therefore we chose to use SW4 to model seismic ground motion in a typical foreland-basin system, to investigate the main controls on the ground motions.

In the paper, we concentrate exclusively on the basin-scale controls on the ground motions. It is well established that the shallow (e.g. top $30 \mathrm{~m}$ ) velocity structure can have a large effect on the amplification of ground shaking, and can vary dramatically over short horizontal distances (e.g. hundreds of metres) [Anderson et al., 1996; Catchings and Lee, 1996; Boore and Joyner, 1997; Bowden and Tsai, 2017; Rajaure et al., 2017]. These smaller-scale effects from the shallow velocity structure will, however, be superimposed on the larger source and basin-scale geometrical effects (which we focus on in this paper), which control the characteristics of the waves entering the near-surface. We emphasise that the effects of the shallow velocity structure will be superimposed on these larger-scale effects that we study here.

\subsection{Model Setup}

We use a simple geometrical model for a foreland basin, as illustrated in Fig. 2. The model encompasses crystalline basement underlying a foreland basin, with seismic waves being produced by a planar, thrust-faulting earthquake at the basin margin. Our model is designed to replicate a typical foreland-basin setting. We impose slip on a fault that underlies the mountain range (although the topography itself is not included in our models), and in which rupture does not propagate into the adjacent basin. The rupture terminates in an up-dip location analogous to being beneath the range front of the mountain belt, as seen in Fig. 1 and observational studies from this tectonic setting 
[Beaumont, 1981; Baranowski et al., 1984; Allen et al., 1986; Nelson et al., 1987; Abers et al., 1988; Fan and Ni, 1989; Molnar and Lyon-Caen, 1989; Cotton et al., 1996; DeCelles and Giles, 1996; Ghose et al., 1997, 1998; Bilham, 2004; Sloan et al., 2011; Avouac et al., 2015; Galetzka et al., 2015; Gavillot et al., 2016; Ainscoe et al., 2017; Wesnousky et al., 2018]. The majority of earthquakes in this tectonic setting do not rupture to the surface (the exception being rare, large events, such as a subset of those on the Himalayan range front [Wesnousky et al., 2017]). We therefore use a geometry in which the slip remains buried at depth, but note that for a minority of earthquakes in this setting there is sometimes some surface slip. The computational domain was set to be wide enough along-strike (X direction in Fig. 2) to encompass a complete earthquake rupture and deep enough ( $\mathrm{Z}$ direction in Fig. 2) to accurately capture all wavelengths of interest (described below). The length of the domain (Y direction in Fig. 2) was determined based on the width of the basin being modelled. The density $(\rho)$ of the crystalline basement was set to $2,700 \mathrm{~kg} \mathrm{~m}^{-3}$ and the $\mathrm{P}-\left(V_{P}\right)$ and S-wave $\left(V_{S}\right)$ velocities were $6,000 \mathrm{~m} \mathrm{~s}^{-1}$ and $3,500 \mathrm{~m} \mathrm{~s}^{-1}$ respectively, yielding a $V_{P} / V_{S}$ ratio of 1.7 , following the findings of Hetényi et al. [2006]; Srinagesh et al. [2011] and Mitra et al. [2011]. Foreland-basin geometries vary significantly depending on the topographic load from neighbouring mountain ranges and the elastic thickness of the foreland, which together control their depth and their width [e.g. Allen et al., 1986; DeCelles and Giles, 1996; Naylor and Sinclair, 2008]. Basin depth and width are varied throughout this study to investigate what control basin structure has on earthquake ground motion. These variables are discussed further in Section 2.2. To replicate the characteristic wedge-shape for the basin, Turcotte and Schubert's (2014) end-load model was adopted. The maximum basin depth was set to the value chosen for each model ('d' on Fig. 2). The shape of the basin-basement interface to the right of the deepest point in Fig. 2 (in the area marked ' $w$ ') was calculated using a flexural profile, with an elastic thickness selected to match the basin width chosen for the model. The basin depth and width are varied between successive models. The basin boundary at the left-hand edge of Fig. 2 was set to dip at $30^{\circ}$ after Ford [2004] and Hetényi et al. [2006]. The material properties of the basin fill $\left(\rho=2250 \mathrm{~kg} \mathrm{~m}^{-3}, V_{P}=4375 \mathrm{~m} \mathrm{~s}^{-1}, V_{S}=2500 \mathrm{~m} \mathrm{~s}^{-1}, V_{P} / V_{S}\right.$ ratio $\left.=1.75\right)$ were selected based on a compilation of global foreland-basin studies [Knopoff, 1971; DeCelles and Giles, 1996; Day et al., 2003; Olsen et al., 2003; Hauksson and Shearer, 2006; Hetényi et al., 2006; Mitra et al., 2011; DeCelles, 2012; Rodgers et al., 2018; Chen and Wei, 2019; Rodgers et al., 2019], and we describe later the effects of changing the chosen values. One of the main assumptions in the model is that both the basement and basin mediums are homogeneous. This simplified approach removes the local effects of internal layering, compaction and porosity variations, which are beyond the scope of this study. The calculated ground motions are therefore wholly a result of the larger basin-scale structure. In our 
initial models, we use no anelastic attenuation, to highlight the effects of source characteristics and basin geometry. We will then describe the results of models that include attenuation.

An earthquake with a moment magnitude $\left(M_{w}\right)$ of 6.5 was simulated on a planar fault with a $10 \mathrm{~km}$ diameter, within the basement material directly down-dip of the base of the foreland basin. We choose this magnitude because such earthquakes are relatively common (Fig. 1) and because the compact rupture allows us to limit the size of our computational domain so that a large number of numerical experiments can be performed. The principles revealed by our results allow us to generalise to other earthquake magnitudes, as discussed below. The rupture begins at the down-dip edge of the rupture patch, in the along-strike centre of the fault plane, and travels radially outwards across the fault plane with a rupture velocity of $2.5 \mathrm{~km} \mathrm{~s}^{-1}$, analogous to observations of past continental thrust-faulting earthquakes [Cotton et al., 1996; Copley et al., 2011; Yi-Ying et al., 2012; Denolle and Shearer, 2016; Kumar et al., 2017; Hayes, 2017]. The imposed slip pattern is circular, with a slip distribution set using the expressions for a circular crack given by Bürgmann et al. [1994]. Using Aki's (1967) relationship between seismic moment, stress drop and fault dimensions for a circular fault, our modelled earthquake has a stress drop of 2.6 MPa, similar to that recorded for the $M_{w} 7.8$ 25th April 2015 Gorkha mainshock $(\Delta \sigma \approx 3.2-3.4 \mathrm{MPa})$ [Lay et al., 2017; Prakash et al., 2016]. The earthquake is formed of sub-sources that we place at $25 \mathrm{~m}$ intervals across the rupture patch. A Gaussian source time function was used for each of the sub-sources. Each sub-source has a set angular frequency of $20 \mathrm{~Hz}$ which corresponds to a fundamental frequency $\left(f_{0}\right)$ of $3.18 \mathrm{~Hz}$ [Sjögreen and Petersson, 2012; Petersson and Sjögreen, 2017b]. For a Gaussian time function, the maximum frequency $\left(f_{\max }\right)$ is $2.5 \times f_{0}$. The minimum resolvable frequency $\left(f_{\min }\right)$ in our model is set by the size of the model domain. This domain is set to be large compared with the rupture dimension so that all frequencies that are produced with appreciable amplitudes by the source are resolvable. For the models below in which attenuation is included, the minimum resolvable frequency is $f_{\max } \times 10^{-2}$, [Sjögreen and Petersson, 2012; Petersson and Sjögreen, 2017b]. Therefore, we model frequencies in the range of $0.08-7.95 \mathrm{~Hz}$, covering the frequencies typical for building oscillation [Murty et al., 2012; Parajuli and Kiyono, 2015; Idham, 2018; Bońkowski et al., 2019], which is important when considering the seismic hazard of a region and building resilience to earthquake shaking. We discuss later the effects of using different source characteristics.

To enable the maximum frequencies produced by our source to be modelled, we require at least six grid points per minimum wavelength $\left(W_{\min }\right)$, which can be calculated by dividing the minimum shear-wave velocity in the model by the maximum frequency, to give a $W_{\min }$ of $314 \mathrm{~m}$ [Petersson and Sjögreen, $2012,2015,2017 \mathrm{~b}]$. Consequently, the grid size was set at $50 \mathrm{~m}$ so that all frequencies within the range 
of $0.08-7.95 \mathrm{~Hz}$ could be accurately resolved.

We extract waveforms for analysis from a line of synthetic stations positioned linearly across the modelled foreland basin, across-strike from the centre of the rupture patch and the hypocentre (Fig. 2). This geometry means that the resulting ground motions are entirely within the plane of the section, with no out-of-plane motions. Therefore, in the subsequent sections, where the horizontal component of the ground motion is discussed, we are referring to that component within the plane of the cross-section.

\subsection{Model Parameter Ranges}

Firstly, we conducted a series of simulations with a range of source depths but no foreland basin, to act as a control in order to evaluate the basin effects in subsequent models. We then varied both the basin and source geometries with the aim of identifying the main controls on the ground shaking. Table 1 outlines each of the parameters that we varied in these models.

The basin geometry was varied first, starting with the basin depth. The depth was modelled between $1 \mathrm{~km}$ and $5 \mathrm{~km}$ at the deepest part ('d' on Fig. 2), spanning the majority of observed foreland-basin depths (see Fig. 1 for a selection, and DeCelles and Giles [1996]). The across-strike basin width was then varied, which we define as the distance between the deepest part of the basin and the furthest edge (i.e. the width of the flexural profile, marked as ' $w$ ' on Fig. 2). The basin width is controlled by the elastic thickness of the foreland and in this study we consider basin widths in the range 50 $200 \mathrm{~km}$, as this spans the observed widths of foreland basins (including in northern India, where the foreland basin is $\sim 200 \mathrm{~km}$ wide).

The source geometry was subsequently varied. Because low-angle thrust earthquakes can occur across a range of distances from a foreland basin (as seen across the Himalayan arc), an earthquake rupture can either rupture to the range front [Lavé et al., 2005; Kumar et al., 2006; Malik et al., 2010; Kumahara and Jayangondaperumal, 2013; Sapkota et al., 2013; Bollinger et al., 2014; Gavillot et al., 2016; Wesnousky et al., 2017] or remain buried at depth [Molnar and Lyon-Caen, 1989; Avouac et al., 2015; Galetzka et al., 2015; Wesnousky et al., 2018]. To account for this variety, we varied the distance between the rupture plane and the basin between $0 \mathrm{~km}$ and $100 \mathrm{~km}$. Likewise, the fault dip was varied between the angle determined from the down-dip extrapolation of a flexural profile for a given basin width (minimum of $13^{\circ}$ in the models below) and a maximum of $45^{\circ}$. This range in fault dip is in line with studies carried out by Hendrix et al. [1992]; Allen et al. [1993, 1994]; Bilham et al. [2003]; Hetényi et al. [2006] and Middleton and Copley [2014] and is illustrated by the fault-plane dips on the 
focal mechanisms shown in Fig. 1.

Subsequent simulations were conducted to determine the effect of the material properties on the ground motion. Table 1 outlines these parameters and the ranges over which they were varied. The seismic-wave speeds within the basin were varied to account for different basin compositions and degree of compaction. The shear-wave velocities $\left(V_{S}\right)$ were varied between $2500 \mathrm{~m} \mathrm{~s}^{-1}$ and $3500 \mathrm{~m} \mathrm{~s}^{-1}$, based on the findings of Hetényi et al. [2006] and Mitra et al. [2011], whilst keeping the $V_{P} / V_{S}$ ratio constant at 1.75. In the calculations described so far, all simulations were run under purely elastic conditions, however, most materials are not elastic and attenuation plays a role in the ground motion produced by earthquakes [Bowden and Tsai, 2017]. Therefore, we conducted a series of simulations with the addition of attenuation. A Quality factor ( $Q$; the inverse of attenuation) is set to be equal for P-waves and S-waves, and is varied in the range 75 to 300, based on studies by Olsen [2000]; Singh et al. [2004]; Hauksson and Shearer [2006]; Shearer et al. [2006]; Srinagesh et al. [2011] and Sharma et al. [2014].

We analyse the Peak Ground Velocities (PGVs) across the computational domain. This ground-motion parameter was selected following studies from Wald et al. [1999] and Wu et al. [2003], which found that PGV has a closer correlation with intensity measures and damage statistics than Peak Ground Acceleration (PGA). Similarly, SW4 simulation results from Rodgers et al. [2018] showed near-zero bias when compared with GMPEs, indicating that the PGV is consistent with the Abrahamson et al. [2014] (ASK14) GMPE predictions in the places they are defined and that the simulations can reproduce the observed path and site effects. In addition to calculating the PGV, we performed spectral analysis by calculating fast Fourier transforms (FFTs) using the Welch [1967] method to determine the frequency dependence of the ground motions. The source magnitude, dimension, and frequency content are kept constant across all the simulations, and we describe later the effects of changing these source characteristics.

\section{Results}

Fig. 3 shows a vertical-component ground-motion time series from models with and without a foreland basin. The cross-sectional profiles illustrate the velocities calculated along a plane positioned in-line with the along-strike centre of the fault plane (see Fig. 2). The cross-sections in Fig. 3 illustrate the lateral propagation of low-amplitude body waves, followed by higher-amplitude, lower-frequency Rayleigh waves. The surface waves dominate the PGV in both scenarios. The dominant wavelength 
of the Rayleigh waves in the case with no basin is $\sim 6 \mathrm{~km}$, which is set by the rupture dimension, the rupture velocity, and the wave-propagation velocity. Fig. 3(b) shows a much more complex wavefield than Fig. 3(a), which arises from two main effects. The existence of the low-velocity sedimentary basin causes dispersion of the surface waves. Additionally, the interaction of the surface waves with the interface between the basin and the basement (including the basin edge) causes the generation of body waves, resulting in a longer and more complex series of S-waves. There is also the transmission of some energy into the basin from the body waves propagating beneath the interface. We will investigate these effects below from the perspective of the controls on the ground motion within the basin.

Spectral analysis was carried out for each of the basin and no-basin reference models illustrated in Fig. 3. Spectra were calculated following Welch [1967], at regular intervals $(10 \mathrm{~km})$ across the model setting, to identify the frequency dependence of the ground motions. Each panel in Fig. 4(b) illustrates how the Power Spectral Density (PSD) amplitudes of the ground motions vary across the range of resolvable frequencies $(0.08-7.95 \mathrm{~Hz})$. It is apparent that the chosen spectra and dimensions of the source dominate the signal, specifically the dominant frequency of the surface waves that are produced. Although there are minor peaks that correspond to body-wave resonance in the basin (at frequencies above $1 \mathrm{~Hz}$, as described below), the frequency of the peak ground motions is controlled by the source spectra. We discuss below the effects of changing the source characteristics and dominant frequency.

\subsection{Effects of basin depth}

Fig. 5 illustrates the effect of basin depth on wave propagation, by comparing a basin that is shallow (maximum depth of $1 \mathrm{~km}$ ) relative to the dominant wavelength of the surface waves $(4 \mathrm{~km}$ in the basin, which is lower than in the basement due to the difference in the propagation velocity) with a basin that has a depth which is similar to the dominant wavelength (maximum depth of $5 \mathrm{~km}$ ). For the shallow basin, the surface waves are strongly dispersed, leading to a long wave train and waveforms that clearly show the earlier parts of the surface waves have lower frequencies than the later parts. For the deeper basin, there is minimal dispersion because the surface waves are dominantly contained within the basin, rather than also sampling the faster underlying basement. However, complex waveforms are visible in the near-field and low-amplitude, high-frequency arrivals are visible before the surface waves in the distant part of the basin (Fig. 5). These features are due to the basin being deep enough for S-waves to resonate within the low-velocity sediments, although they are of lower amplitude than the surface waves. 
Fig. 6 shows the results of the same simulations as in Fig. 5 (and additionally for a basin depth of $3 \mathrm{~km}$ ), plotted as peak ground velocity as a function of distance. The PGVs for the no-basin reference models are also included for comparison. For both cases, we plot the vertical and horizontal components, of which, the vertical ground motions are larger for all models of varying basin depths, due to the geometry of the source. Fig. 6(c) illustrates that the PGVs are greatest for shallow basins, which is a result of the source being positioned down-dip of the flexural-base of the basin (dashed lines in Fig. 6a). This geometry means that shallow basins in our models are associated with shallow, thrust-faulting earthquakes, which result in larger PGVs at the surface. Ulloa and Lozos [2020] also discussed the effect that source depth has on ground shaking, with shallower events resulting in higher ground motions. This source-depth effect dominates the signal. By normalising with respect to the peak PGV for each model (Fig. 6b) we can isolate the effects of the basin geometry, which can be seen across two different length scales: short $(\sim 10-20 \mathrm{~km})$ and long $(\sim 100 \mathrm{~km})$. Through the centre of the basin (between distances of $40-140 \mathrm{~km}$ ) the surface waves cause pronounced differences in the normalised PGV values, producing variations in the ground motions in a pattern that spans the entire width of the basin. Body-wave resonance within the basin causes short length-scale undulations in the normalised PGVs, which is superimposed upon the surface-wave effects, with a wavelength of kilometres to tens of kilometres.

The differences between model results that occur on the length scale of the entire basin result from the relation between the dominant wavelength of the surface waves and the depth of the basin. For the case of the shallow basin, dispersion of the surface waves results in a rapid decrease in PGV over a short distance, as the energy is spread over a longer-duration but lower-amplitude wave train. There are also differences in the PGV values between models where the basins are of a similar or larger depth than the dominant surface wavelength within the basin (which is $\sim 4 \mathrm{~km}$ ). This effect arises because where the surface wavelength is similar to the basin depth and the waves interact with the velocity contrast at the base, surface-wave amplification occurs [Bard and Bouchon, 1980; Joyner, 2000; Olsen, 2000; Day et al., 2008; Denolle et al., 2014; Bowden and Tsai, 2017]. Where the basin is too deep for the base to interact with the surface wave, this effect does not occur. The PGV in both of these cases decays rapidly at the distal part of the basin, where it becomes shallow and dispersion occurs. This effect is why the $1 \mathrm{~km}$-deep basin model in Fig. 6(c) has much lower PGVs in the far-field (especially the vertical component), than the corresponding no-basin reference model (in which such dispersion doesn't occur). The effects of the lateral separation between the source and the edge of the basin will be discussed below. 
The basin depth also has a small effect on the position of the peak PGV. In Fig. 6, the basin and source depths increase together, as the fault is a down-dip extension of the base of the foreland basin. In Fig. 6(b) the location of the maximum PGV moves basinward for deeper basins. This effect is not seen in the numerical experiments in Fig. 7(b) where the basin depth remains the same but the source depth varies. This finding implies that this effect arises due to the changes in basin depth and not source depth. However, this movement in the peak PGV has a minor control on the ground motions when compared with the other factors considered in this paper, such as the relationship between the basin depth and dominant wavelength of the source.

\subsection{Effects of basin width}

Fig. 7 illustrates the effect of basin width on PGV. The vertical and horizontal components of the ground motion are plotted, and similarly to Fig. 6 , the vertical ground motions are largest. The PGVs for the no-basin reference models are also included for comparison. Fig. 7 demonstrates the short- and long-wavelength characteristics of body-wave resonance and surface-wave propagation respectively, as described above. The PGVs for wide basins $(200 \mathrm{~km})$ decrease gradually over large distances. In comparison, narrow basins $(50 \mathrm{~km})$ see a rapid decrease in PGV over short distances (Fig. 7c) as the shallow, distal part of the basin is encountered and a dispersive wave train is produced, causing the duration of shaking to increase and the amplitude to decrease. This effect is a result of when the basin becomes shallow enough that significant surface-wave dispersion begins to occur. Therefore, it is the basin width that defines when appreciable dispersion begins.

Unlike basin depth, Fig. 7 (c) illustrates only small differences $(<7 \%)$ in the PGV at the edge of the basin closest to the source. This effect is due to the underlying effect that source depths vary slightly with changes in the dip of the basin floor (and it's down-dip continuation which hosts the earthquake), which are in turn caused by varying the basin width (Fig. 7a).

\subsection{Effects of the source-to-basin distance}

Fig. 8 illustrates the effect of the source-to-basin distance on wave propagation. This numerical experiment is based on the observation that earthquake ruptures sometimes reach the range front, but in other cases remain buried at depth [Bilham, 2004; Lavé et al., 2005; Kumar et al., 2006; Malik et al., 2010; Kumahara and Jayangondaperumal, 2013; Sapkota et al., 2013; Bollinger et al., 2014; Avouac et al., 2015; Gavillot et al., 2016; Wesnousky et al., 2017, 2018]. In this plot, Fig. 8(b) shows the 
vertical PGV whilst Fig. 8(c) illustrates the horizontal PGV, both of which have the no-basin reference models included for comparison. The vertical ground motions are larger than the horizontal ground motions, consistent with the results in Sections 3.1 and 3.2. Similarly, within the basins, the no-basin reference models have lower PGVs compared to the basin models, irrespective of their source-to-basin distance. Beyond the basins, the PGV values for models including basins are lower than those for models without, due to the surface-wave dispersion that occurs as the waves propagate through the shallow parts of the basins. These numerical simulations also show the short- and long-wavelength characteristics of body-wave resonance and surface-wave propagation, as discussed above.

The near-source PGVs differ depending on the source depth, and the values in the proximal part of the basin depend on the position of the source relative to the basin. The ruptures that are more distant from the basin result in lower increases in PGV as the waves enter the basin (Figs 8b and 8c). The increase happens because of the change in material properties between the basement and the basin. This effect is lower (in percentage terms, compared to the near-source PGV) for sources distant from the basin because as the source moves away from the basin, a smaller proportion of the total energy is directed into the basin (due to it occupying a smaller proportion of the cross-sectional area into which waves are radiated by the source). For sources positioned $25-50 \mathrm{~km}$ from the basin, the amplification in the basin is such that the PGV there roughly equals that in the near-source region, producing a double-peak in the ground motion pattern (Figs 8b and 8c).

\subsection{Effects of fault dip}

Fig. 9 illustrates the effect of the fault dip on PGV. The vertical and horizontal components of the ground motion are plotted, as well as the no-basin reference models for comparison. This numerical experiment was inspired by the observation that some mountain range fronts are characterised by low-angle thrusting along planes down-dip of the foreland basin (e.g. the Himalayas), whilst others are characterised by higher-angle faulting on planes dipping at $\sim 45^{\circ}$ beneath the mountains (e.g. the northern Tien Shan), as seen in Fig. 1. Shallow-dipping faults, like the one that is in line with the base of the basin $\left(13.5^{\circ}\right)$ on Fig. 9(a), produced higher PGVs than the steeper-dipping faults $\left(25^{\circ}\right.$ \& $45^{\circ}$. This is a result of two controls: source depth and the angle of the incident wave.

For a given depth to the top of the earthquake rupture, steepening the dip moves the centroid (the slip-weighted average depth of slip) to deeper depths, resulting in lower PGV values (as described above). A second important effect revealed by Fig. 9 relates to the resulting wave propagation. The 
amount of energy that is either reflected or refracted off the basin-basement interface is controlled by the angle of the incident wave. Shallow fault dips result in waves propagating into the basin from shallow angles, and therefore being trapped by internal reflection within the basin (using Snell's law, we determined that the basin has a critical angle of $46^{\circ}$ ). For rupture on steeply-dipping faults, a greater proportion of the energy is incident on the surface and basin floor at higher angles. Therefore, more of this energy is transmitted into the interior of the Earth, rather than trapped in the basin. Also plotted on Fig. 8 is the PGV in the horizontal component. As in the models described above, this component is lower-amplitude than the vertical. The two components become more equal as the fault dip increases, because more equal amplitudes of vertical and horizontal motion in the resulting seismic waves are produced by steeper-dipping faults. However, both components decrease as the fault dip increases (due to the change in source depth), which is a larger control on the ground motion.

\subsection{Effect of material properties}

The material properties of the basin fill also affect the amount of ground shaking that is produced. Fig. 10 illustrates the effect of basin seismic velocity on wave propagation. These results are expressed as a function of the $\mathrm{S}$-wave velocity, but the $\mathrm{P}$-wave velocity has also been varied to maintain a $V_{P} / V_{S}$ ratio of 1.75. The vertical and horizontal components of the ground motion are plotted on Fig. 10, as well as the no-basin reference models for comparison. As seen previously, the vertical PGVs are higher than the horizontal values. This effect results from the source geometry. Both components decrease as the basin S-wave velocity increases. All the resultant ground motions from the basin models exceed the no-basin reference PGVs in the locations of the basins, but are lower in the far-field due to the surface-wave dispersion that occurs as the waves propagate through the shallow parts of the basins.

There are three main effects shown on Fig. 10. Firstly, the absolute value of the PGV varies, because the velocity controls the degree of amplification caused when the waves enter the basin. Secondly, the wavelengths of the body-wave resonance and the broad signal caused by surface-wave amplification and dispersion are changed slightly. This is due to the variable basin velocities and different reflection coefficients at the basin-basement interface, resulting in different dominant wavelengths and resonant frequencies in the basin interior. Thirdly, the far-field PGV is slightly higher for higher basin velocities, because the lower velocity contrast with the basement means that less energy is lost due to body-wave excitation by the surface waves along the interface between the basin and basement. However, the differences between these models are small compared with the effects of the source and basin geometry described above. 
Fig. 11 illustrates the effect of attenuation on the distribution of PGV in the basin. The quality factor is set to be equal for $\mathrm{P}$-waves and $\mathrm{S}$-waves and is varied in the range $75-300$, based on the results of Olsen [2000]; Singh et al. [2004]; Hauksson and Shearer [2006]; Shearer et al. [2006]; Srinagesh et al. [2011] and Sharma et al. [2014]. In this plot, Fig. 11(b) shows the vertical PGV whilst Fig. 11(c) illustrates the horizontal PGV, both of which have the no-basin reference models included for comparison. In agreement with the previous sections, the vertical ground motions are larger than the horizontal ground motions, and the no-basin reference models have lower PGVs than the basin models. Similar to previous numerical simulations, Fig. 11 shows the short- and long-wavelength characteristics of body-wave resonance and surface-wave propagation. As expected, as attenuation increases the PGV decreases, and this effect is most pronounced in the distal part of the basin, where the waves have propagated furthest. A quality factor of $\sim 100$ is likely to be relevant to the bulk of the basin fill (i.e. not the near-surface sediments), with quality factors $\geq 400-500$ for the deeper crustal material [Schlotterbeck and Abers, 2001; Hauksson and Shearer, 2006; Shearer et al., 2006]. In comparison to the model results described above, attenuation has a similar-sized effect on the magnitude of PGV within the foreland as the basin geometry, but a smaller effect on the magnitude of PGV than the source geometry (i.e. depth and dip).

\section{Discussion}

The modelling results described above show that the source characteristics have a larger effect on PGV than the basin geometry. Of particular importance are the source depth, location relative to the basin margin, and fault dip, all of which can vary significantly between mountain ranges and sometimes along-strike within a given range (e.g. Fig. 1; Maggi et al. [2000]; Sibson and Xie [1998]; Bilham et al. [2003]; Bilham [2004]; Jackson et al. [2008]; Middleton and Copley [2014]; Bai et al. [2019]). However, these quantities can often be difficult to estimate in advance of earthquakes (e.g. it was not widely expected that some large earthquakes on the Himalayan megathrust in Nepal would fail to rupture to the surface, as was the case with the 2015 Gorkha earthquake [Avouac et al., 2015; Galetzka et al., 2015]). The results presented above suggest that these source attributes have a more important impact on basin-scale ground shaking than the basin geometry itself.

The basin geometry does, however, also play a role in controlling ground shaking. The relative length scale of the basin depth and the dominant wavelength of the surface waves controls whether appreciable surface-wave dispersion occurs, resulting in longer-duration but lower-amplitude ground 
motions. Basin depth and width both contribute to controlling the locations where appreciable dispersion occurs, for a given earthquake. This concept allows us to extend our analysis to a wider range of source magnitudes and spatial sizes than that considered above. Increasing the magnitude of the source also involves increasing the spatial size of the rupture, due to the observed relationship between magnitude and fault dimension [Scholz, 1982; Scholz et al., 1986; Cowie and Scholz, 1992; Scholz, 1997]. Increasing the earthquake magnitude will increase the resulting PGV (because of the amount of energy release), in addition to increasing the dominant wavelength of the surface waves (due to the increasing fault size), and therefore change the range of basin geometries over which surface-wave dispersion becomes important. These effects are conceptually displayed in Fig. 12. The red curve represents the case for a given magnitude, such as the $M_{w} 6.5$ considered here. Deep basins and the associated deep earthquakes produce low-amplitude ground shaking. Shallow basins and the associated shallow earthquakes result in high-amplitude ground motions that are rapidly dispersed during propagation through the basin. There is a middle ground in which the basin and source are shallow enough that high-amplitude surface waves are produced, but that the basin is deep enough to produce little dispersion across most of the basin width. If the magnitude of the earthquake is increased, the basin needs to be deeper to prevent dispersion, but the PGV is increased for all basin depths due to the magnitude increase. The effect is, therefore, to move the curve up and to the right on the graph shown in Fig. 12. A corollary of this effect is that lateral differences in basin depth (e.g. as shown across the Indo-Gangetic and Tarim basins in Fig. 1; Chatterjee [1971]; Lee [1985]; Graham et al. [1990]; Nishidai and Berry [1990]; Cobbold et al. [1993]; Royden [1993]; Huafu et al. [1994]; Yang and Liu [2002]; Bilham et al. [2003]; Hetényi et al. [2006]; Mitra et al. [2011]; Srinagesh et al. [2011]; Li et al. [2013]; Wei et al. [2013]; Morin et al. [2019]) can have an important consequence in terms of the magnitudes of earthquakes for which PGV values will be similar across large areas of the basins, or decay rapidly with distance.

In addition to the spatial size of the fault rupture, other effects can also play a role in controlling the dominant wavelength of the resulting surface waves. For example, the rupture velocity of the earthquake (which controls the importance of directionality effects) and the intrinsic frequency content of the source (e.g. relating to the length-scale of individual asperities within the rupture patch) can control the wavelength of the resulting waves. The stress drop of the earthquake, which controls the spatial size of the rupture for a given moment release, can have a similar effect. Likewise, the seismic velocity of the material in which the source is embedded. It is beyond the scope of this manuscript to consider each of these effects. However, our results presented above provide a means to infer their role in the resulting ground motions using our finding that, following source depth, the next most 
dominant control on the ground motions is the relative length scales of the basin depth and dominant surface-wave wavelength. Therefore, all effects that involve increasing the dominant wavelength of the surface waves (reducing the intrinsic frequency of the source, reducing the stress drop, reducing the rupture velocity and increasing the ambient seismic velocity) will have an effect that is equivalent to the subset of the consequences of increasing the seismic moment that are based on the effects on the dominant wavelength, as described above. Such changes will therefore result in surface-wave dispersion effects being more important for a given basin depth, or less important if these parameters are changed in the opposite direction. Based on the geological setting and mode of formation of foreland basins, we have concentrated on thrust-faulting earthquake ruptures. However, we note that the effects of the relative sizes of the dominant wavelength of the waves and the basin depth will also be true for other types of events (i.e. strike-slip earthquakes within the mountains bounding a basin), but the specific ground motions (e.g. the relative importance of vertical and horizontal motions) will depend on the details of the source geometry.

Having identified the main controls on earthquake shaking in foreland basins from range-front thrust earthquakes, we considered the controls on the amount of ground shaking produced by normal-faulting events, often observed in the flexing, underlying crystalline basement in foreland-basin systems [DeCelles and Giles, 1996]. Assessing the seismic hazard resulting from such normal faults is difficult as they are often too deep to observe any expression of the extension at the surface, but it is worthwhile comparing their likely effects with those of the range-front thrust-faulting events.

We conducted a series of simulations using the same geometrical model setup for a foreland basin as illustrated in Fig. 2, but changed the fault mechanism and location in order to simulate a normal-faulting earthquake in the basement, underlying the basin. The normal fault was positioned with the up-dip termination of the fault at the base of the foreland basin at a depth of $2 \mathrm{~km}$, with a dip of $45^{\circ}$. The remaining source parameters (magnitude, dimension, rupture velocity and frequency content) and material properties (seismic velocities and densities) remained unchanged from our original setup outlined in Section 2.1, to allow for comparisons to be made between the thrustand normal-faulting earthquake ground motions. Therefore, as the rupture dimension, the rupture velocity and the wave propagation velocities remained the same for both earthquake scenarios, the dominant wavelengths in the basement material $(\sim 6 \mathrm{~km})$ and foreland basin $(\sim 4 \mathrm{~km})$ also remain the same.

Fig. 13(a) illustrates the cross-sectional setup and a snapshot of the resultant wavefield produced by the normal-faulting earthquake rupture. Fig. 13(b) shows the results of the simulation, plotted as PGV as 
a function of distance. Both vertical and horizontal components of the ground motion are illustrated, with the vertical PGV being higher in both the thrust- and normal-faulting models. Fig. 13(a) demonstrates the lateral propagation of low-amplitude body waves, followed by higher-amplitude lower-frequency Rayleigh waves which dominate the PGV, as was the case with the range-front thrust events modelled above. After the initial up-dip rupture through crystalline basement material producing high PGVs, the surface waves disperse causing a rapid decrease in PGV over a short distance $(\sim 10 \mathrm{~km})$ from the fault (Fig. 13b), as a result of the shallow $(\sim 1.7-2.1 \mathrm{~km})$ basin depth. The PGVs for the waves that propagate towards the range front at distances of $\sim 20-45 \mathrm{~km}$ are higher than the foreland-propagating waves at distances of $\sim 70-105 \mathrm{~km}$ (Figs 13a and 13b). The laterally-varying basin depth therefore plays a role in counteracting the hanging-wall effect, which tends to increase the ground motions in the hanging wall relative to the footwall. As the waves propagate towards the range front, the basin increases to a maximum depth of $3 \mathrm{~km}$ and therefore gets closer to the dominant wavelength of the surface waves. The waves interact with the velocity contrast at the basin-basement interface, causing surface-wave amplification and higher PGVs [Bard and Bouchon, 1980; Joyner, 2000; Olsen, 2000; Day et al., 2008; Denolle et al., 2014; Bowden and Tsai, 2017]. The higher PGVs in the mountainward direction compared to the basinward direction are also partially due to rupture-directivity effects. The waves propagating away from the range front, however, are strongly dispersed, and the basin becomes too shallow for the S-waves to resonate within the low-velocity sediments.

When comparing the normal- and thrust-faulting ground motions, there are two controlling variables: the source depth and the fault dip. As the thrust fault has both a shallower source depth and a more shallowly-dipping fault plane than the normal fault, it produces higher PGVs (Fig. 13b). In terms of length scales, the thrust-faulting earthquake resulted in longer-wavelength, basin-wide effects, whilst the normal-faulting earthquake yielded shorter-wavelength effects which were more localised to the fault region. This effect arises because of the dip effects discussed above, with more of the normal-faulting energy being reflected into the deep Earth rather than propagating through the basin, and due to the waves being generated in a region with a shallower basin depth.

Although we have changed a number of geometrical parameters between the normal-faulting and thrust-faulting earthquakes in this comparison, these changes are based upon observations from foreland-basin settings. Although the details of the comparison depend upon our chosen parameters, some overall concepts can be demonstrated. When comparing the two rupture scenarios (range-front, thrust-faulting vs distal, normal-faulting) in a foreland collisional setting, it is clear that range-front 
thrust faults yield larger-magnitude ground motions than buried normal faults. Wirth et al. [2019] also showed that shallow, thrust earthquakes produced higher amplification in the Seattle and Tacoma Basins, compared to deep, normal earthquakes which could suggest that the source depth remains the dominant control on ground motion, despite the tectonic setting. However, the results presented above demonstrate that, for a given magnitude, normal faulting in the underlying basin can result in higher PGV for localised regions of the basin than for an equivalent range-front thrust.

\section{Conclusion}

Large populations are present in cities built on or near foreland basins, and often information about their seismic risk is either unknown or limited. Although body-wave resonance has long been a well-understood phenomenon, surface waves and their path effects are less understood, often resulting in an underestimation of the seismic hazard in some regions. Seismic-wave-propagation modelling in this study has shown that the amount of initial ground motion produced largely depends on the source depth, whilst the basin structure (width and depth) determines how much of this energy gets dispersed. The maximum ground velocities are produced when the basin depth matches the dominant wavelength produced by the source. The basin width, however, determines how rapidly this ground motion decreases with distance, given that the width determines where the basin becomes shallow enough for dispersion to begin.

\section{Acknowledgements}

AOK was funded by an EPSRC iCASE PhD Studentship in collaboration with Ove Arup and Partners Ltd. AOK and AC designed the project and performed the numerical calculations. AOK processed and analysed the results with input from AC. AOK wrote the manuscript with editing support from AC. The authors wish to thank James Jackson, Camilla Penney and Sam Wimpenny for comments on earlier versions of the manuscript and also to Grace Campbell and Matthew Free for useful discussions. $\mathrm{AOK}$ and $\mathrm{AC}$ would also like to thank the Editor, Associate Editor, Kyle Withers and an anonymous reviewer for constructive comments on the manuscript. 


\section{Data Availability}

The SW4 open-source code was developed at Lawrence Livermore National Laboratory and is distributed by the Computational Infrastructure for Geodynamics (www.geodynamics.org/ cig/software/sw4). In Fig. 1 we used an array of freely-available datasets for topographic, earthquake, fault and population density data. ETOPO2 (2-minute gridded global relief) data was downloaded from the NOAA National Centers for Environmental Information web page (https://www.ngdc.noaa.gov/mgg/global/etopo2.html). Earthquake data was sourced from various individual studies referenced in the manuscript and has been compiled by Wimpenny [2020] into a Global Waveform Catalogue, available at https://comet.nerc.ac.uk/gwfm_catalogue/. Fault traces were plotted from Taylor and Yin [2009] and Styron et al. [2010]. Gridded population density data (GPWv4) was sourced from the Socioeconomic Data and Applications Center web page (https://sedac.ciesin.columbia.edu/data/collection/gpw-v4), whilst all other population-relation statistics were retrieved from Cox [2019]. All figures have been produced using Generic Mapping Tools v6 [Wessel et al., 2019] and Inkscape v0.92.3 [Inkscape Project, 2018]. 


\section{References}

Aagaard, B. T., Brocher, T. M., Dolenc, D., Dreger, D., Graves, R. W., Harmsen, S., Hartzell, S., Larsen, S., McCandless, K., Nilsson, S., Petersson, N. A., Rodgers, A., Sjögreen, B., and Zoback, M. L. (2008). Ground-motion modeling of the 1906 San Francisco earthquake, part II: Ground-motion estimates for the 1906 earthquake and scenario events. Bulletin of the Seismological Society of America, 98(2):1012-1046.

Aagaard, B. T., Graves, R. W., Rodgers, A., Brocher, T. M., Simpson, R. W., Dreger, D., Petersson, N. A., Larsen, S. C., Ma, S., and Jachens, R. C. (2010). Ground-Motion Modeling of Hayward Fault Scenario Earthquakes, Part II: Simulation of Long-Period and Broadband Ground Motions. Bulletin of the Seismological Society of America, 100(6):2945-2977.

Abdrakhmatov, K. E., Walker, R. T., Campbell, G. E., Carr, A. S., Elliott, A., Hillemann, C., Hollingsworth, J., Landgraf, A., Mackenzie, D., Mukambayev, A., Rizza, M., and Sloan, R. A. (2016). Multisegment rupture in the 11 July 1889 Chilik earthquake ( $M w ~ 8.0-8.3$ ), Kazakh Tien Shan, interpreted from remote sensing, field survey, and paleoseismic trenching. Journal of Geophysical Research: Solid Earth, 121(6):4615-4640.

Abers, G., Bryan, C., Roecker, S., and McCaffrey, R. (1988). Thrusting of the Hindu Kush over the Southeastern Tadjik Basin, Afghanistan: Evidence from two large earthquakes. Tectonics, $7(1): 41-56$.

Abrahamson, N. A. and Silva, W. J. (1997). Empirical response spectral attenuation relations for shallow crustal earthquakes. Seismological Research Letters, 68(1):94-127.

Abrahamson, N. A., Silva, W. J., and Kamai, R. (2014). Summary of the ASK14 ground motion relation for active crustal regions. Earthquake Spectra, 30(3):1025-1055.

Ainscoe, E. A., Elliott, J. R., Copley, A., Craig, T. J., Li, T., Parsons, B. E., and Walker, R. T. (2017). Blind Thrusting, Surface Folding, and the Development of Geological Structure in the $\mathrm{M}_{w} 6.32015$ Pishan (China) Earthquake. Journal of Geophysical Research: Solid Earth, 122(11):9359-9382.

Aki, K. (1967). Scaling law of seismic spectrum. Journal of Geophysical Research, 72(4):1217-1231.

Allen, P. A., Homewood, P., and Williams, G. D. (1986). Foreland basins: an introduction. In Foreland Basins, 8:3-12.

Allen, M. B., Windley, B. F., Zhang, C., and Guo, J. (1993). Evolution of the Turfan basin, Chinese central Asia. Tectonics, 12(4):889-896.

Allen, M. B., Windley, B. F., and Zhang, C. (1994). Cenozoic tectonics in the Urumqi-Korla region of the Chinese Tien Shan. In Active Continental Margins - Present and Past, 406-416.

Anderson, J. G., Lee, Y., Zeng, Y., and Day, S. (1996). Control of strong motion by the upper 30 meters. Bulletin of the Seismological Society of America, 86(6):1749-1759.

Asano, K., Sekiguchi, H., Iwata, T., Yoshimi, M., Hayashida, T., Saomoto, H., and Horikawa, H. (2016). Modelling of wave propagation and attenuation in the Osaka sedimentary basin, western Japan, during the 2013 Awaji Island earthquake. Geophysical Journal International, 204(3):1678-1694. 
Avouac, J. P., Meng, L., Wei, S., Wang, T., and Ampuero, J. P. (2015). Lower edge of locked Main Himalayan Thrust unzipped by the 2015 Gorkha earthquake. Nature Geoscience, 8(9):708-711.

Bai, L., Klemperer, S. L., Mori, J., Karplus, M. S., Ding, L., Liu, H., Li, G., Song, B., and Dhakal, S. (2019). Lateral variation of the Main Himalayan Thrust controls the rupture length of the 2015 Gorkha earthquake in Nepal. Science Advances, 5(6):eaav0723.

Bande, A., Radjabov, S., Sobel, E. R., and Sim, T. (2017). Cenozoic palaeoenvironmental and tectonic controls on the evolution of the northern Fergana Basin. Geological Society, London, Special Publications, 427(1):313-335.

Baranowski, J., Armbruster, J., Seeber, L., and Molnar, P. (1984). Focal depths and fault-plane solutions of earthquakes and active tectonics of the Himalaya. Journal of Geophysical Research, 89(B8):6918-6928.

Bard, P. Y. and Bouchon, M. (1980). The seismic response of sediment-filled valleys. Part 2. The case of incident P and SV waves. Bulletin of the Seismological Society of America, 70(5):1921-1941.

Bard, P. Y. and Bouchon, M. (1985). The two-dimensional resonance of sediment-filled valleys. Bulletin of the Seismological Society of America, 75(2):519-541.

Bayasgalan, A., Jackson, J., and McKenzie, D. (2005). Lithosphere rheology and active tectonics in Mongolia: Relations between earthquake source parameters, gravity and GPS measurements. Geophysical Journal International, 163(3):1151-1179.

Beaumont, C. (1981). Foreland basins. Geophysical Journal International, 65(2):291-329.

Berberian, M., Jackson, J. A., Qorashi, M., Talebian, M., Khatib, M., and Priestley, K. (2000). The 1994 Sefidabeh earthquakes in eastern Iran: blind thrusting and bedding-plane slip on a growing anticline, and active tectonics of the Sistan suture zone. Geophysical Journal International, 142(2):283-299.

Bernard, M., Shen-Tu, B., Holt, W. E., and Davis, D. M. (2000). Kinematics of active deformation in the Sulaiman Lobe and Range, Pakistan. Journal of Geophysical Research: Solid Earth, 105(B6):13253-13279.

Bhattarai, M., Adhikari, L. B., Gautam, U. P., Laurendeau, A., Labonne, C., Hoste-Colomer, R., Sebe, O., and Hernandez, B. (2015). Overview of the large 25 April 2015 Gorkha, Nepal, earthquake from accelerometric perspectives. Seismological Research Letters, 86(6):1540-1548.

Bian, W., Hornung, J., Liu, Z., Wang, P., and Hinderer, M. (2010). Sedimentary and palaeoenvironmental evolution of the Junggar Basin, Xinjiang, northwest China. Geological Society, London, Special Publications, 90(3):175-186.

Bielak, J., Graves, R. W., Olsen, K. B., Taborda, R., Ramírez-Guzmán, L., Day, S. M., Ely, G. P., Roten, D., Jordan, T. H., Maechling, P. J., Urbanic, J., Cui, Y., and Juve, G. (2010). The ShakeOut earthquake scenario: Verification of three simulation sets. Geophysical Journal International, 180(1):375-404. 
Bilham, R. (2001). Slow tilt reversal of the Lesser Himalaya between 1862 and 1992 at $78^{\circ} \mathrm{E}$, and bounds to the southeast rupture of the 1905 Kangra earthquake. Geophysical Journal International, 144(3):713-728.

Bilham, R. (2004). Earthquakes in India and the Himalaya: tectonics, geodesy and history. Annals of Geophysics, 47(2-3):839-858.

Bilham, R., Bendick, R., and Wallace, K. (2003). Flexure of the Indian plate and intraplate earthquakes. Journal of Earth System Science, 112(3):315-329.

Bollinger, L., Sapkota, S. N., Tapponnier, P., Klinger, Y., Rizza, M., Van Der Woerd, J., Tiwari, D. R., Pandey, R., Bitri, A., and Bes de Berc, S. (2014). Estimating the return times of great Himalayan earthquakes in eastern Nepal: Evidence from the Patu and Bardibas strands of the Main Frontal Thrust. Journal of Geophysical Research: Solid Earth, 119(9):7123-7163.

Bońkowski, P. A., Zembaty, Z., and Minch, M. Y. (2019). Engineering analysis of strong ground rocking and its effect on tall structures. Soil Dynamics and Earthquake Engineering, 116:358-370.

Bonner, J., Herrmann, R. B., Harkrider, D., and Pasyanos, M. (2008). The surface wave magnitude for the 9 October 2006 North Korean nuclear explosion. Bulletin of the Seismological Society of America, 98(5):2498-2506.

Boore, D. M. and Atkinson, G. M. (2008). Ground-motion prediction equations for the average horizontal component of PGA, PGV, and 5\%-damped PSA at spectral periods between $0.01 \mathrm{~s}$ and 10.0 s. Earthquake Spectra, 24(1):99-138.

Boore, D. M. and Joyner, W. B. (1997). Site amplifications for generic rock sites. Bulletin of the Seismological Society of America, 87(2):327-341.

Bosboom, R., Mandic, O., Dupont-Nivet, G., Proust, J. N., Ormukov, C., and Aminov, J. (2017). Late Eocene palaeogeography of the proto-Paratethys Sea in Central Asia (NW China, southern Kyrgyzstan and SW Tajikistan). Geological Society, London, Special Publications, 427(1):565-588.

Bowden, D. C. and Tsai, V. C. (2017). Earthquake ground motion amplification for surface waves. Geophysical Research Letters, 44(1):121-127.

Brunet, M. F., Sobel, E. R., and McCann, T. (2017). Geological evolution of Central Asian basins and the western Tien Shan range. Geological Society, London, Special Publications, 427(1):1-17.

Burbank, D. W., Beck, R. A., and Mulder, T. (1996). The Himalayan foreland basin. World and regional geology, 149-190.

Bürgmann, R., Pollard, D. D., and Martel, S. J. (1994). Slip distributions on faults: effects of stress gradients, inelastic deformation, heterogeneous host-rock stiffness, and fault interaction. Journal of Structural Geology, 16(12):1675-1690.

Burtman, V. and Molnar, P. (1993). Geological and geophysical evidence for deep subduction of continental crust beneath the Pamir. Special Publications of the Geological Society of America, 281.

Campbell, K.W. and Bozorgnia, Y. (2008). NGA ground motion model for the geometric mean horizontal component of PGA, PGV, PGD and 5\% damped linear elastic response spectra for periods ranging from 0.01 to 10 s. Earthquake Spectra, 24(1):139-171. 
Campbell, K., Abrahamson, N., Power, M., Chiou, B., Bozorgnia, Y., Shantz, T., and Roblee, C. (2009). Next Generation Attenuation (NGA) project: empirical ground motion prediction equations for active tectonic regions. In Sixth International Conference on Urban Earthquake Engineering, March, 3-4.

Campbell, G. E., Walker, R. T., Abdrakhmatov, K., Schwenninger, J. L., Jackson, J., Elliott, J. R., and Copley, A. (2013). The Dzhungarian fault: Late Quaternary tectonics and slip rate of a major right-lateral strike-slip fault in the northern Tien Shan region. Journal of Geophysical Research: Solid Earth, 118(10):5681-5698.

Carroll, A. R., Yunhai, L., Graham, S. A., Xuchang, X., Hendrix, M. S., Jinchi, C., and McKnight, C. L. (1990). Junggar basin, northwest China: trapped Late Paleozoic ocean. Tectonophysics, 181(1-4):1-14.

Catchings, R. D. and Lee, W. H. K. (1996). Shallow velocity structure and Poisson's ratio at the Tarzana, California, strong-motion accelerometer site. Bulletin of the Seismological Society of America, 86(6):1704-1713.

Center for International Earth Science Information Network (CIESIN). (2016). Gridded Population of the World, Version 4 (GPWv4): Population Density. NASA Socioeconomic Data and Applications Center (SEDAC) Palisades, NY.

Chaljub, E., Cornou, C., Guéguen, P., Causse, M., and Komatitsch, D. (2005). Spectral-element modeling of 3D wave propagation in the alpine valley of Grenoble, France. In Geophysical Research Abstracts, 7:05225.

Chaljub, E., Moczo, P., Tsuno, S., Bard, P. Y., Kristek, J., Käser, M., Stupazzini, M., and Kristekova, M. (2010). Quantitative comparison of four numerical predictions of 3D ground motion in the Grenoble Valley, France. Bulletin of the Seismological Society of America, 100(4):1427-1455.

Chapman, J. B., Carrapa, B., DeCelles, P. G., Worthington, J., Mancin, N., Cobianchi, M., Stoica, M., Wang, X., Gadoev, M., and Oimahmadov, I. (2019). The Tajik Basin: A composite record of sedimentary basin evolution in response to tectonics in the Pamir. Basin Research, 32(3):525-545.

Chatterjee, S. N. (1971). On the dispersion of Love waves and crust-mantle structure in the Gangetic Basin. Geophysical Journal International, 23(2):129-138.

Chen, W. P. (1988). A Brief Update on the Focal Depths of Intracontinental Earthquakes and their Correlations with Heat Flow and Tectonic Age. Seismological Research Letters, 59(4):263-272.

Chen, W. P. and Molnar, P. (1990). Source parameters of earthquakes and intraplate deformation beneath the Shillong Plateau and the northern Indoburman Ranges. Journal of Geophysical Research, 95(B8):12527-12552.

Chen, M. and Wei, S. (2019). The 2015 Gorkha, Nepal, Earthquake Sequence: II. Broadband Simulation of Ground Motion in Kathmandu. Bulletin of the Seismological Society of America, 109(2):672-687.

Chen, W. P. and Yang, Z. (2004). Earthquakes beneath the Himalayas and Tibet: evidence for strong lithospheric mantle. Science, 304(5679):1949-1952. 
Chiou, B. S. J. and Youngs, R. R. (2008). An NGA model for the average horizontal component of peak ground motion and response spectra. Earthquake Spectra, 24(1):173-215.

Cobbold, P. R., Davy, P., Gapais, D., Rossello, E. A., Sadybakasov, E., Thomas, J. C., Tondji Biyo, J. J., and De Urreiztieta, M. (1993). Sedimentary basins and crustal thickening. Sedimentary Geology, 86(1-2):77-89.

Copley, A., Avouac, J. P., Hollingsworth, J., and Leprince, S. (2011). The $2001 \mathrm{M}_{w} 7.6$ Bhuj earthquake, low fault friction, and the crustal support of plate driving forces in India. Journal of Geophysical Research: Solid Earth, 116:B08405.

Cotton, F., Campillo, M., Deschamps, A., and Rastogi, B. K. (1996). Rupture history and seismotectonics of the 1991 Uttarkashi, Himalaya earthquake. Tectonophysics, 258(1-4):35-51.

Coutand, I., Strecker, M. R., Arrowsmith, J. R., Hilley, G., Thiede, R. C., Korjenkov, A., and Omuraliev, M. (2002). Late Cenozoic tectonic development of the intramontane Alai Valley, (Pamir-Tien Shan region, central Asia): An example of intracontinental deformation due to the Indo-Eurasia collision. Tectonics, 21(6):3-1-3-20.

Cowie, P. A. and Scholz, C. H. (1992). Displacement-length scaling relationship for faults: data synthesis and discussion. Journal of Structural Geology, 14(10):1149-1156.

Cox, W. (2019). Demographia World Urban Areas: 15th Annual Edition. Demographia.

Craig, T. J., Copley, A., and Jackson, J. A. (2012). Thermal and tectonic consequences of India underthrusting Tibet. Earth and Planetary Science Letters, 353-354:231-239.

Day, S. M., Bielak, J., Dreger, D., Graves, R., Larsen, S., Olsen, K. B., and Pitarka, A. (2003). Tests of 3D elastodynamic codes: Final report for Lifelines Project 1A02. Pacific Earthquake Engineering Research Center.

Day, S. M., Graves, R., Bielak, J., Dreger, D., Larsen, S., Olsen, K. B., Pitarka, A., and Ramirez-Guzman, L. (2008). Model for basin effects on long-period response spectra in southern California. Earthquake Spectra, 24(1):257-277.

DeBatist, M., Imbo, Y., Vermeesch, P., Klerkx, J., Giralt, S., Delvaux, D., Lignier, V., Beck, C., Kalugin, I., and Abdrakhmatov, K. E. (2002). Bathymetry and sedimentary environments of Lake Issyk-Kul, Kyrgyz Republic (Central Asia): a large, high-altitude, tectonic lake. In Lake Issyk-Kul: its natural environment, 101-123.

DeCelles, P. G. (2012). Foreland basin systems revisited: Variations in response to tectonic settings. Tectonics of Sedimentary Basins: Recent Advances, 405-426.

DeCelles, P. G. and Giles, K. A. (1996). Foreland basin systems. Basin Research, 8(2):105-123.

Denolle, M. A. and Shearer, P. M. (2016). New perspectives on self-similarity for shallow thrust earthquakes. Journal of Geophysical Research: Solid Earth, 121(9):6533-6565.

Denolle, M. A., Miyake, H., Nakagawa, S., Hirata, N., and Beroza, G. C. (2014). Long-period seismic amplification in the Kanto Basin from the ambient seismic field. Geophysical Research Letters, 41(7):2319-2325. 
Douglas, J. (2019). Ground motion prediction equations 1964-2019. PEER Report 2011, 102.

Drake, L. A. (1980). Love and Rayleigh waves in an irregular soil layer. Bulletin of the Seismological Society of America, 70(2):571-582.

England, P. and Jackson, J. (2011). Uncharted seismic risk. Nature Geoscience, 4(6):348-349.

Eyidogan, H. and Jackson, J. (1985). A seismological study of normal faulting in the Demirci, Alaşehir and Gediz earthquakes of 1969-70 in western Turkey: implications for the nature and geometry of deformation in the continental crust. Geophysical Journal of the Royal Astronomical Society, 81(3):569-607.

Fan, G. and Ni, J. F. (1989). Source parameters of the 13 February 1980, Karakorum earthquake. Bulletin of the Seismological Society of America, 79(4):945-954.

Fan, G., Ni, J. F., and Wallace, T. C. (1994). Active tectonics of the Pamirs and Karakorum. Journal of Geophysical Research, 99(B4):7131-7160.

Fang, X., Zhang, W., Meng, Q., Gao, J., Wang, X., King, J., Song, C., Dai, S., and Miao, Y. (2007). High-resolution magnetostratigraphy of the Neogene Huaitoutala section in the eastern Qaidam Basin on the NE Tibetan Plateau, Qinghai Province, China and its implication on tectonic uplift of the NE Tibetan Plateau. Earth and Planetary Science Letters, 258(1-2):293-306.

Ford, M. (2004). Depositional wedge tops: interaction between low basal friction external orogenic wedges and flexural foreland basins. Basin Research, 16(3):361-375.

Frankel, A., Stephenson, W., and Carver, D. (2009). Sedimentary basin effects in Seattle, Washington: Ground-motion observations and 3D simulations. Bulletin of the Seismological Society of America, 99(3):1579-1611.

Galetzka, J., Melgar, D., Genrich, J. F., Geng, J., Owen, S., Lindsey, E. O., Xu, X., Bock, Y., Avouac, J. P., Adhikari, L. B., Upreti, B. N., Pratt-Sitaula, B., Bhattarai, T. N., Sitaula B. P., Moore, A., Hudnut, K. W., Szeliga, W., Normandeau, J., Fend, M., Flouzat, M., Bollinger, L., Shrestha, P., Koirala, B., Gautam, U., Bhatterai, M., Gupta, R., Kandel, T., Timsina, C., Sapkota, S. N., Rajaure, S., and Maharjan, N. (2015). Slip pulse and resonance of the Kathmandu basin during the 2015 Gorkha earthquake, Nepal. Science, 349(349):1091-1095.

Gavillot, Y., Meigs, A., Yule, D., Heermance, R., Rittenour, T., Madugo, C., and Malik, M. (2016). Shortening rate and Holocene surface rupture on the Riasi fault system in the Kashmir Himalaya: active thrusting within the Northwest Himalayan orogenic wedge. Geological Society of America Bulletin, 128(7-8):1070-1094.

Ghose, S., Mellors, R. J., Korjenkov, A. M., Hamburger, M. W., Pavlis, T. L., Pavlis, G. L., Omuraliev, M., Mamyrov, E., and Muraliev, A. R. (1997). The $\mathrm{M}_{S}=7.31992$ Suusamyr, Kyrgyzstan, earthquake in the tien shan: 2. Aftershock focal mechanisms and surface deformation. Bulletin of the Seismological Society of America, 87(1):23-38.

Ghose, S., Hamburger, M. W., and Ammon, C. J. (1998). Source parameters of moderate-sized earthquakes in the tien Shan, central Asia from regional moment tensor inversion. Geophysical Research Letters, 25(16):3181-3184. 
Goode, J. K., Burbank, D. W., and Bookhagen, B. (2011). Basin width control of faulting in the Naryn Basin, south-central Kyrgyzstan. Tectonics, 30(6).

Graham, S. A., Brassell, S., Carroll, A. R., Xiao, X., Demaison, G., McKnight, C. L., Liang, Y., Chu, J., and Hendrix, M. S. (1990). Characteristics of selected petroleum source rocks, Xianjiang Uygur autonomous region, Northwest China. AAPG bulletin, 74(4):493-512.

Graves, R. W. and Pitarka, A. (2004). Broadband time history simulation using a hybrid approach. In Thirteenth World Conference on Earthquake Engineering Conference Proceedings, Vancouver, BC. Paper 1098.

Graves, R. and Pitarka, A. (2016). Kinematic ground-motion simulations on rough faults including effects of 3D stochastic velocity perturbations. Bulletin of the Seismological Society of America, 106(5):2136-2153.

Graves, R. W., Aagaard, B. T., Hudnut, K. W., Star, L. M., Stewart, J. P., and Jordan, T. H. (2008). Broadband simulations for $\mathrm{M}_{w} 7.8$ southern San Andreas earthquakes: Ground motion sensitivity to rupture speed. Geophysical research letters, 35(22).

Grützner, C., Carson, E., Walker, R. T., Rhodes, E. J., Mukambayev, A., Mackenzie, D., Elliott, J. R., Campbell, G., and Abdrakhmatov, K. (2017). Assessing the activity of faults in continental interiors: Palaeoseismic insights from SE Kazakhstan. Earth and Planetary Science Letters, 459:93-104.

Gülerce, Z., Kamai, R., Abrahamson, N. A., and Silva, W. J. (2013). NGA-West2 ground motion prediction equations for vertical ground motions. PEER Report, 24:3-48.

Harmsen, S., Hartzell, S., and Liu, P. (2008). Simulated ground motion in Santa Clara Valley, California, and vicinity from $M \geq 6.7$ scenario earthquakes. Bulletin of the Seismological Society of America, 98(3):1243-1271.

Hartzell, S., Harmsen, S., and Frankel, A. (2010). Effects of 3D random correlated velocity perturbations on predicted ground motions. Bulletin of the Seismological Society of America, 100(4):1415-1426.

Hauksson, E. and Shearer, P. M. (2006). Attenuation models $\left(\mathrm{Q}_{P}\right.$ and $\left.\mathrm{Q}_{S}\right)$ in three dimensions of the southern California crust: Inferred fluid saturation at seismogenic depths. Journal of Geophysical Research: Solid Earth, 111(B5).

Hayes, G. P. (2017). The finite, kinematic rupture properties of great-sized earthquakes since 1990. Earth and Planetary Science Letters, 468:94-100.

Hendrix, M. S., Graham, S. A., Carroll, A. R., Sobel, E. R., McKnight, C. L., Schulein, B. J., and Wang, Z. (1992). Sedimentary record and climatic implications of recurrent deformation in the Tian Shan: Evidence from Mesozoic strata of the north Tarim, south Junggar, and Turpan basins, northwest China. Geological Society of America Bulletin, 104(1):53-79.

Hetényi, G., Cattin, R., Vergne, J., and Nábělek, J. L. (2006). The effective elastic thickness of the India Plate from receiver function imaging, gravity anomalies and thermomechanical modelling. Geophysical Journal International, 167(3):1106-1118. 
Holt, W. E., Ni, J. F., Wallace, T. C., and Haines, A. J. (1991). The active tectonics of the eastern Himalayan syntaxis and surrounding regions. Journal of Geophysical Research, 96(B9):14595-14632.

Huafu, L., Howell, D. G., Dong, J., Dongsheng, C., Shimin, W., Chuming, C., Valin, Z. C., and Yangshen, S. (1994). Rejuvenation of the Kuqa foreland basin, northern flank of the Tarim basin, northwest China. International Geology Review, 36(12):1151-1158.

Idham, N. C. (2018). Earthquake failures on buildings and the role of architect on building safety. Journal of Architecture and Built Environment, 45(2):153-164.

Idriss, I. M. (2008). An NGA empirical model for estimating the horizontal spectral values generated by shallow crustal earthquakes. Earthquake Spectra, 24(1):217-242.

Imperatori, W. and Gallovič, F. (2017). Validation of 3D velocity models using earthquakes with shallow slip: Case study of the $2014 \mathrm{M}_{w} 6.0$ South Napa, California, Event. Bulletin of the Seismological Society of America, 107(2):1019-1026.

Inkscape Project. (2018). Inkscape v0.92.3. https://inkscape.org.

Jackson, J. A., Priestley, K., Allen, M., and Berberian, M. (2002). Active tectonics of the South Caspian Basin. Geophysical Journal International, 148(2):214-245.

Jackson, J., McKenzie, D., Priestley, K., and Emmerson, B. (2008). New views on the structure and rheology of the lithosphere. Journal of the Geological Society, 165(2):453-465.

Joyner, W. B. (2000). Strong motion from surface waves in deep sedimentary basins. Bulletin of the Seismological Society of America, 90(6B):S95-S112.

Kawase, H. and Aki, K. (1989). A study on the response of a soft basin for incident S, P, and Rayleigh waves with special reference to the long duration observed in Mexico City. Bulletin of the Seismological Society of America, 79(5):1361-1382.

Khaimov, R. N. (1986). The Paleozoic sediments of the Fergana Basin: Their potential for oil and gas. International Geology Review, 28(1):75-79.

Kirsty, M. J. and Simpson, D. W. (1980). Seismicity changes preceding two recent central Asian earthquakes. Journal of Geophysical Research: Solid Earth, 85(B9):4829-4837.

Knopoff, L. (1971). Attenuation. In Mantle and Core in Planetary Physics, 146-156.

Kober, M., Seib, N., Kley, J., and Voigt, T. (2013). Thick-skinned thrusting in the northern Tien Shan foreland, Kazakhstan: structural inheritance and polyphase deformation. Geological Society, London, Special Publications, 377(1):19-42.

Kufner, S. K., Schurr, B., Ratschbacher, L., Murodkulov, S., Abdulhameed, S., Ischuk, A., Metzger, S., and Kakar, N. (2018). Seismotectonics of the Tajik basin and surrounding mountain ranges. Tectonics, 37(8):2404-2424.

Kumahara, Y. and Jayangondaperumal, R. (2013). Paleoseismic evidence of a surface rupture along the northwestern Himalayan Frontal Thrust (HFT). Geomorphology, 180:47-56. 
Kumar, S., Wesnousky, S. G., Rockwell, T. K., Briggs, R. W., Thakur, V. C., and Jayangondaperumal, R. (2006). Paleoseismic evidence of great surface rupture earthquakes along the Indian Himalaya. Journal of Geophysical Research: Solid Earth, 111(B3).

Kumar, A., Singh, S. K., Mitra, S., Priestley, K. F., and Dayal, S. (2017). The 2015 April 25 Gorkha (Nepal) earthquake and its aftershocks: Implications for lateral heterogeneity on the Main Himalayan Thrust. Geophysical Journal International, 208(2):992-1008.

Lastrico, R. M., Duke, C. M., and Ohta, Y. (1972). Effects of site and propagation path on recorded strong earthquake motions. Bulletin of the Seismological Society of America, 62(4):933-954.

Lavé, J., Yule, D., Sapkota, S., Basant, K., Madden, C., Attal, M., and Pandey, R. (2005). Evidence for a great Medieval earthquake ( 1100 AD) in the central Himalayas, Nepal. Science, 307(5713):1302-1305.

Lay, T., Ye, L., Koper, K. D., and Kanamori, H. (2017). Assessment of teleseismically-determined source parameters for the April 25, $2015 \mathrm{M}_{w} 7.9$ Gorkha, Nepal earthquake and the May 12, 2015 $\mathrm{M}_{w} 7.2$ aftershock. Tectonophysics, 714:4-20.

Lebrun, B., Hatzfeld, D., and Bard, P. Y. (2002). Site effect study in urban area: experimental results in Grenoble (France). In Earthquake Microzoning, 2543-2557.

Lee, K. Y. (1985). Geology of the Tarim Basin with special emphasis on petroleum deposits, Xinjiang Uygur Zizhiqu, Northwest China. US Geological Survey.

Li, Y. J., Zhao, Y., Sun, L. D., Song, W. J., Zheng, D. M., Liu, Y. L., Wang, D. X., Hu, J. F., and Zhang, Q. R. (2013). Meso-Cenozoic extensional structures in the northern Tarim Basin, NW China. International Journal of Earth Sciences, 102(4):1029-1043.

Lozano, L., Herraiz, M., and Singh, S. K. (2009). Site effect study in central Mexico using H/V and SSR techniques: Independence of seismic site effects on source characteristics. Soil Dynamics and Earthquake Engineering, 29(3):504-516.

Macaulay, E. A., Sobel, E. R., Mikolaichuk, A., Wack, M., Gilder, S., Mulch, A., Fortuna, A. B., Hynek, S., and Apayarov, F. (2016). The sedimentary record of the Issyk Kul basin, Kyrgyzstan: climatic and tectonic inferences. Basin Research, 28(1):57-80.

Maggi, A., Jackson, J. A., McKenzie, D., and Priestley, K. (2000). Earthquake focal depths, effective elastic thickness, and the strength of the continental lithosphere. Geology, 28(6):495.

Malik, J. N., Sahoo, A. K., Shah, A. A., Shinde, D. P., Juyal, N., and Singhvi, A. K. (2010). Paleoseismic evidence from trench investigation along Hajipur fault, Himalayan Frontal Thrust, NW Himalaya: implications of the faulting pattern on landscape evolution and seismic hazard. Journal of Structural Geology, 32(3):350-361.

Meza-Fajardo, K. C., Semblat, J. F., Chaillat, S., and Lenti, L. (2016). Seismic-Wave Amplification in 3D Alluvial Basins: 3D/1D Amplification Ratios from Fast Multipole BEM Simulations. Bulletin of the Seismological Society of America, 106(3):1267-1281.

Middleton, T. A. and Copley, A. (2014). Constraining fault friction by re-examining earthquake nodal plane dips. Geophysical Journal International, 196(2):671-680. 
Mitra, S., Priestley, K., Bhattacharyya, A. K., and Gaur, V. K. (2005). Crustal structure and earthquake focal depths beneath northeastern India and southern Tibet. Geophysical Journal International, 160(1):227-248.

Mitra, S., Kainkaryam, S. M., Padhi, A., Rai, S. S., and Bhattacharya, S. N. (2011). The Himalayan foreland basin crust and upper mantle. Physics of the Earth and Planetary Interiors, 184(1-2):34-40.

Molnar, P. and Lyon-Caen, H. (1989). Fault plane solutions of earthquakes and active tectonics of the Tibetan Plateau and its margins. Geophysical Journal International, 99(1):123-154.

Molnar, P. and Tapponnier, P. (1978). Active tectonics of Tibet. Journal of Geophysical Research, 83(B11):5361.

Molnar, P. and Chen, W. P. (1983). Focal depths and fault plane solutions of earthquakes under the Tibetan plateau. Journal of Geophysical Research, 88(B2):1180-1196.

Morin, J., Jolivet, M., Barrier, L., Laborde, A., Li, H., and Dauteuil, O. (2019). Planation surfaces of the Tian Shan Range (Central Asia): Insight on several 100 million years of topographic evolution. Journal of Asian Earth Sciences, 177:52-65.

Murty, C. V., Goswani, R., Vijayanarayanan, A., and Mehta, V. V. (2012). Some concepts in earthquake behaviour of buildings. Gujarat State Disaster Management Authority, Government of Gujarat.

Naylor, M. and Sinclair, H. D. (2008). Pro- vs. retro-foreland basins. Basin Research, 20(3):285-303.

Nelson, M. R., McCaffrey, R., and Molnar, P. (1987). Source parameters for 11 earthquakes in the Tien Shan, central Asia, determined by P and SH waveform inversion. Journal of Geophysical Research, 92(B12):12629.

Nishidai, T. and Berry, J. L. (1990). Structure and hydrocarbon potential of the Tarim Basin (NW China) from satellite imagery. Journal of Petroleum Geology, 13(1):35-58.

Olsen, K. B. (2000). Site amplification in the Los Angeles basin from three-dimensional modeling of ground motion. Bulletin of the Seismological Society of America, 90(6B):S77-S94.

Olsen, K. B. and Schuster, G. T. (1995). Causes of low-frequency ground motion amplification in the Salt Lake Basin: the case of the vertically incident P wave. Geophysical Journal International, 122(3):1045-1061.

Olsen, K. B., Day, S. M., and Bradley, C. R. (2003). Estimation of Q for long-period (> 2 sec) waves in the Los Angeles basin. Bulletin of the Seismological Society of America, 93(2):627-638.

Parajuli, R. R. and Kiyono, J. (2015). Ground motion characteristics of the 2015 Gorkha earthquake, survey of damage to stone masonry structures and structural field tests. Frontiers in Built Environment, 123.

Pathier, E., Fielding, E. J., Wright, T. J., Walker, R., Parsons, B. E., and Hensley, S. (2006). Displacement field and slip distribution of the 2005 Kashmir earthquake from SAR imagery. Geophysical Research Letters, 33:L20310. 
Pei, Y., Paton, D. A., Wu, K., and Xie, L. (2017). Subsurface structural interpretation by applying trishear algorithm: An example from the Lenghu5 fold-and-thrust belt, Qaidam Basin, Northern Tibetan Plateau. Journal of Asian Earth Sciences, 143:343-353.

Petersson, N. A. and Sjögreen, B. (2012). Stable and efficient modeling of anelastic attenuation in seismic wave propagation. Communications in Computational Physics, 12(1):193-225.

Petersson, N. A. and Sjögreen, B. (2014). Super-grid modeling of the elastic wave equation in semi-bounded domains. Communications in Computational Physics, 16(4):913-955.

Petersson, N. A. and Sjögreen, B. (2015). Wave propagation in anisotropic elastic materials and curvilinear coordinates using a summation-by-parts finite difference method. Communications in Computational Physics, 299:820-841.

Petersson, N. A. and Sjögreen, B. (2017a). SW4 v2.0. Computational Infrastructure for Geodynamics, Davis, CA. http://doi.org/10.5281/zenodo.1063644.

Petersson, N. A. and Sjögreen, B. (2017b). User's guide to SW4, version 2.0. Lawrence Livermore National Laboratory Tech. Rept. LLNL-SM-741439, 1-119.

Power, M., Chiou, B., Abrahamson, N., Bozorgnia, Y., Shantz, T., and Roblee, C. (2008). An overview of the NGA project. Earthquake Spectra, 24(1):3-21.

Prakash, R., Singh, R. K., and Srivastava, H. N. (2016). Nepal earthquake 25 April 2015: source parameters, precursory pattern and hazard assessment. Geomatics, Natural Hazards and Risk, $7(6): 1769-1784$.

Rajaure, S. Asimaki, D. Thompson, E. M. Hough, S. Martin, S. Ampuero, J. P. Dhital, M. R. Inbal, A. Takai, N. Shigefuji, M., Bijukchhen, S., Ichiyanagi, M., Sasatani, T., and Paudel, L. (2017). Characterizing the Kathmandu Valley sediment response through strong motion recordings of the 2015 Gorkha earthquake sequence. Tectonophysics, 714:146-157.

Rial, J.A., Saltzman, N. G., and Ling, H. (1992). Earthquake-induced resonance in sedimentary basins. American Scientist, 80(6):566-578.

Rodgers, A. J. (2019). Earthquake Ground Motion Simulations on the Sierra High-Performance Computing System. Lawrence Livermore National Laboratory Tech. Rept. LLNL-TR-793741.

Rodgers, A. J., Pitarka, A., Petersson, N. A., Sjögreen, B., and McCallen, D. B. (2018). Broadband $(0-4 \mathrm{~Hz})$ ground motions for a magnitude 7.0 Hayward fault earthquake with three-dimensional structure and topography. Geophysical Research Letters, 45(2):739-747.

Rodgers, A. J., Petersson, N. A., Pitarka, A., McCallen, D. B., Sjogreen, B., and Abrahamson, N. (2019). Broadband (0-5 Hz) Fully Deterministic 3D Ground-Motion Simulations of a Magnitude 7.0 Hayward Fault Earthquake: Comparison with Empirical Ground-Motion Models and 3D Path and Site Effects from Source Normalized Intensities. Seismological Research Letters, 90(3):1268-1284.

Royden, L. H. (1993). The tectonic expression slab pull at continental convergent boundaries. Tectonics, 12(2):303-325. 
Rupakhety, R., Olafsson, S., and Halldorsson, B. (2017). The 2015 Mw 7.8 Gorkha Earthquake in Nepal and its aftershocks: analysis of strong ground motion. Bulletin of Earthquake Engineering, 15(7):2587-2616.

Sadigh, K., Chang, C. Y., Egan, J. A., Makdisi, F., and Youngs, R. R. (1997). Attenuation relationships for shallow crustal earthquakes based on California strong motion data. Seismological Research Letters, 68(1):180-189.

Sanchez-Sesma, F. J. (1987). Site effects on strong ground motion. Soil Dynamics and Earthquake Engineering, 6(2):124-132.

Sapkota, S. N., Bollinger, L., Klinger, Y., Tapponnier, P., Gaudemer, Y., and Tiwari, D. (2013). Primary surface ruptures of the great Himalayan earthquakes in 1934 and 1255. Nature Geoscience, 6(1):71-76.

Schlotterbeck, B. A. and Abers, G. A. (2001). Three-dimensional attenuation variations in southern California. Journal of Geophysical Research: Solid Earth, 106(B12):30719-30735.

Scholz, C. H. (1982). Scaling laws for large earthquakes: consequences for physical models. Bulletin of the Seismological Society of America, 72(1):1-14.

Scholz, C. H. (1997). Size distributions for large and small earthquakes. Bulletin of the Seismological Society of America, 87(4):1074-1077.

Scholz, C. H., Aviles, C. A., and Wesnousky, S. G. (1986). Scaling differences between large interplate and intraplate earthquakes. Bulletin of the Seismological Society of America, 76(1):65-70.

Sharma, J., Chopra, S., and Roy, K. S. (2014). Estimation of source parameters, quality factor (QS), and site characteristics using accelerograms: Uttarakhand Himalaya region. Bulletin of the Seismological Society of America, 104(1):360-380.

Shearer, Peter M., Prieto, G. A., and Hauksson, E. (2006). Comprehensive analysis of earthquake source spectra in southern California. Journal of Geophysical Research: Solid Earth, 111(B6).

Sibson, R. H. and Xie, G. (1998). Dip range for intracontinental reverse fault ruptures: Truth not stranger than friction?. Bulletin of the Seismological Society of America, 88(4):1014-1022.

Singh, S. K., Garcia, D., Pacheco, J. F., Valenzuela, R., Bansal, B. K., and Dattatrayam, R. S. (2004). Q of the Indian Shield. Bulletin of the Seismological Society of America, 94(4):1564-1570.

Sjögreen, B. and Petersson, N. A. (2012). A fourth order accurate finite difference scheme for the elastic wave equation in second order formulation. Journal of Scientific Computing, 52(1):17-48.

Sloan, R. A., Jackson, J. A., McKenzie, D., and Priestley, K. (2011). Earthquake depth distributions in central Asia, and their relations with lithosphere thickness, shortening and extension. Geophysical Journal International, 185(1):1-29.

Sobel, E. R., Oskin, M., Burbank, D., and Mikolaichuk, A. (2006). Exhumation of basement-cored uplifts: Example of the Kyrgyz Range quantified with apatite fission track thermochronology. Tectonics, 25(2). 
Srinagesh, D., Singh, S.K., Chadha, R. K., Paul, A., Suresh, G., Ordaz, M., and Dattatrayam, R. S. (2011). Amplification of seismic waves in the central Indo-Gangetic basin, India. Bulletin of the Seismological Society of America, 101(5):2231-2242.

Styron, R., Taylor, M., and Okoronkwo, K. (2010). Database of active structures from the Indo-Asian collision. Eos, Transactions American Geophysical Union, 91(20):181-182.

Taborda, R. and Bielak, J. (2013). Ground-motion simulation and validation of the 2008 Chino Hills, California, earthquake. Bulletin of the Seismological Society of America, 103(1):131-156.

Tapponnier, P. and Molnar, P. (1979). Active faulting and Cenozoic tectonics of the Tien Shan, Mongolia, and Baykal regions. Journal of Geophysical Research: Solid Earth, 84(B7):3425-3459.

Taylor, M. and Yin, A. (2009). Active structures of the Himalayan-Tibetan orogen and their relationships to earthquake distribution, contemporary strain field, and Cenozoic volcanism. Geosphere, 5(3):199-214.

Thompson, S. C., Weldon, R. J., Rubin, C. M., Abdrakhmatov, K., Molnar, P., and Berger, G. W. (2002). Late Quaternary slip rates across the central Tien Shan, Kyrgyzstan, central Asia. Journal of Geophysical Research: Solid Earth, 107(B9):7-1-7-32.

Turcotte, D. and Schubert, G. (2014). Geodynamics 3rd edn. Cambridge University Press.

Ulloa, S. and Lozos, J. C. (2020). Surface Displacement and Ground Motion from Dynamic Rupture Models of Thrust Faults with Variable Dip Angles and Burial Depths. Bulletin of the Seismological Society of America.

Voigt, S., Weber, Y., Frisch, K., Bartenstein, A., Hellwig, A., Petschick, R., Bahr, A., Pross, J., Koutsodendris, A., Voigt, T., Verestek, V., and Appel, E. (2017). Climatically forced moisture supply, sediment flux and pedogenesis in Miocene mudflat deposits of south-east Kazakhstan, Central Asia. The Depositional Record, 3(2):209-232.

Wald, D. J., Quitoriano, V., Heaton, T. H., and Kanamori, H. (1999). Relationships between peak ground acceleration, peak ground velocity, and modified Mercalli intensity in California. Earthquake Spectra, 15(3):557-564.

Wei, H. H., Meng, Q. R., Ding, L., and Li, Z. Y. (2013). Tertiary evolution of the western Tarim basin, northwest China: A tectono-sedimentary response to northward indentation of the Pamir salient. Tectonics, 32(3):558-575.

Welch, P. D. (1967). The Use of Fast Fourier Transform for the Estimation of Power Spectra: A Method Based on Time Averaging Over Short, Modified Periodograms. IEEE Transactions on Audio and Electroacoustics, 15(2):70-73.

Wesnousky, G., Kumahara, Y., Chamlagain, D., Pierce, I. K., Karki, A., and Gautam, D. (2017). Geological observations on large earthquakes along the Himalayan frontal fault near Kathmandu, Nepal. Earth and Planetary Science Letters, 457:366-375.

Wesnousky, S. G., Kumahara, Y., Nakata, T., Chamlagain, D., and Neupane, P. (2018). New observations disagree with previous interpretations of surface rupture along the Himalayan 
frontal thrust during the great 1934 Bihar-Nepal earthquake. Geophysical Research Letters, $45(6): 2652-2658$.

Wessel, P., Luis, J. F., Uieda, L., Scharroo, R., Wobbe, F., Smith, W. H. F., and Tian, D. (2019). The generic mapping tools version 6. Geochemistry, Geophysics, Geosystems, 20(11):5556-5564.

Wimpenny, S. (2020). Global Waveform Catalogue (gWFM) v1.0. Centre for Observation and Modelling of Earthquakes, Volcanoes and Tectonics (COMET). http://doi.org/10.5281/zenodo.3376300.

Wirth, E. A., Vidale, J. E., Frankel, A. D., Pratt, T. L., Marafi, N. A., Thompson, M., and Stephenson, W. J. (2019). Source-dependent amplification of earthquake ground motions in deep sedimentary basins. Geophysical Research Letters, 46(12):6443-6450.

Wu, Y. M., Teng, T. L., Shin, T. C., and Hsiao, N. C. (2003). Relationship between peak ground acceleration, peak ground velocity, and intensity in Taiwan. Bulletin of the Seismological Society of America, 93(1):386-396.

Xuezhong, S., Jiaru, Z., Huiji, F., Romahov, U., and Kaydash, F. (2008). The basement structure in Junggar basin: deep-sounding by converted waves of earthquakes. Xinjiang Petroleum Geology, 29(4):439-444.

Yang, Y. and Liu, M. (2002). Cenozoic deformation of the Tarim plate and the implications for mountain building in the Tibetan Plateau and the Tian Shan. Tectonics, 21(6):9-1-9-17.

Yin, A., Dang, Y.Q., Zhang, M., Chen, X. H., and McRivette, M. W. (2008). Cenozoic tectonic evolution of the Qaidam basin and its surrounding regions (Part 3): Structural geology, sedimentation, and regional tectonic reconstruction. Geological Society of America Bulletin, 120(7-8):847-876.

Yi-Ying, W., Kuo-Fong, M., and Oglesby, D. D. (2012). Variations in rupture speed, slip amplitude and slip direction during the $2008 \mathrm{M}_{w} 7.9$ Wenchuan Earthquake. Geophysical Journal International, 190(1):379-390.

Yu, X., Guo, Z., Zhang, Q., Cheng, X., Du, W., Wang, Z., and Bian, Q. (2017). Denan Depression controlled by northeast-directed Olongbulak Thrust Zone in northeastern Qaidam basin: Implications for growth of northern Tibetan Plateau. Tectonophysics, 717:116-126.

Zhao, J., Jin, Z., Mooney, W. D., Okaya, N., Wang, S., Gao, X., Tang, L., Pei, S., Liu, H., and $\mathrm{Xu}$, Q. (2013). Crustal structure of the central Qaidam basin imaged by seismic wide-angle reflection/refraction profiling. Tectonophysics, 584:174-190.

Zhou, J., Xu, F., Wang, T., Cao, A., and Yin, C. (2006). Cenozoic deformation history of the Qaidam Basin, NW China: Results from cross-section restoration and implications for Qinghai-Tibet Plateau tectonics. Earth and Planetary Science Letters, 243(1-2):195-210. 


\section{Tables}

Table 1: Geometrical parameters and material properties that were varied during the seismic-wave-propagation modelling and the ranges over which they were varied.

\begin{tabular}{lll}
\hline Variable & Notation & Range \\
\hline
\end{tabular}

\section{Geometrical Parameters}

Basin depth

$\begin{array}{cc}d & 0-5 \mathrm{~km} \\ w & 50-200 \mathrm{~km} \\ - & 0-100 \mathrm{~km} \\ - & 13.5-45.0^{\circ}\end{array}$

Basin width

Source-to-basin distance*

$13.5-45.0^{\circ}$

\section{Material Properties}

Basin shear-wave velocity

$V_{S} \quad 2.5-3.5 \mathrm{~km} \mathrm{~s}^{-1}$

Attenuation (Quality Factor)

Q $\quad 75-300$

${ }^{*}$ This refers to the distance between the up-dip termination of the rupture patch and the maximum basin depth. 


\section{Figures}

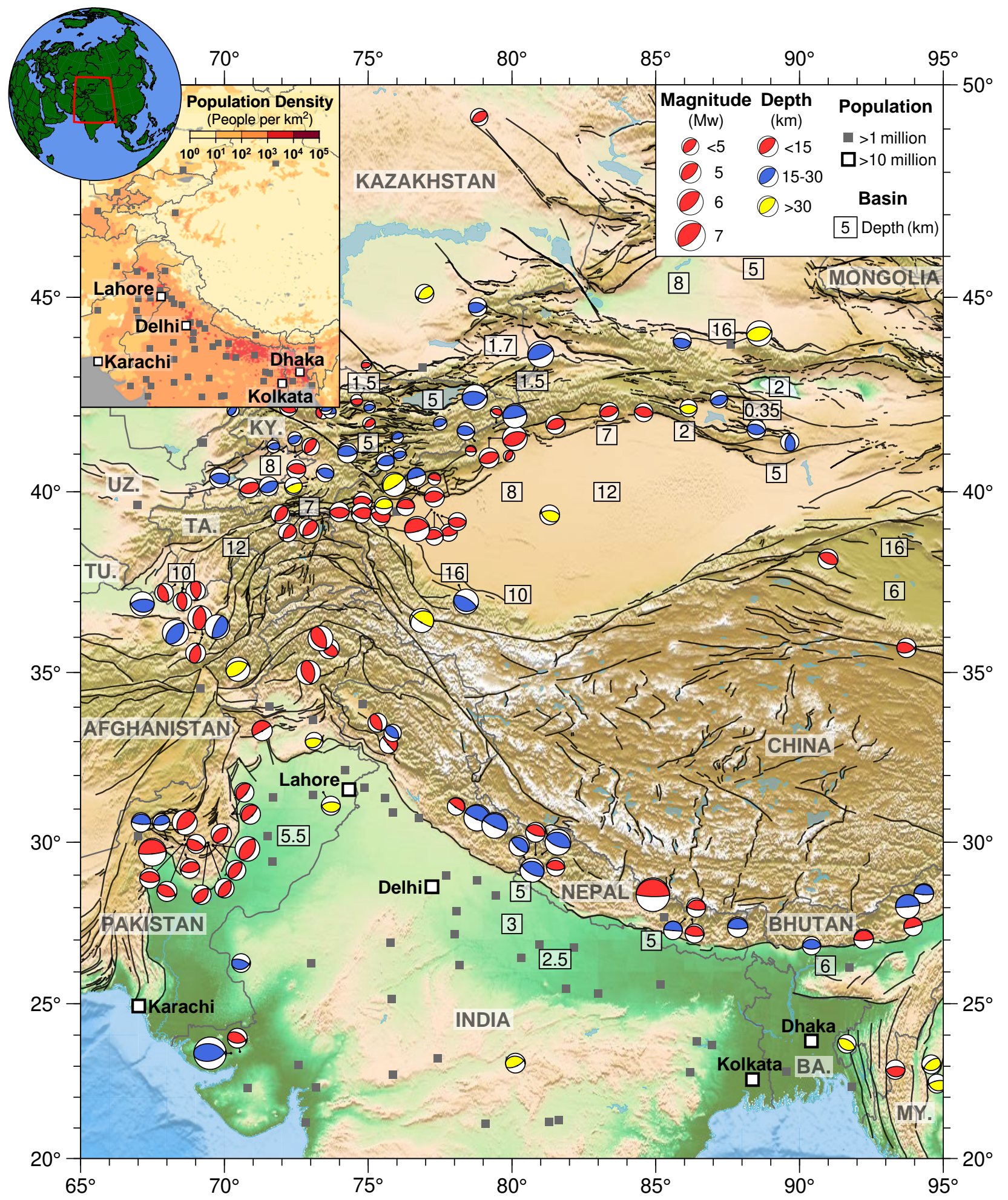

Figure 1: Map of Central Asia illustrating the interplay between topography, seismicity and population. Earthquake focal mechanisms are shown for thrust-faulting earthquakes; scaled in size by their moment magnitudes and coloured according to their centroid depth in kilometres [Molnar and Tapponnier, 1978; Kirsty and Simpson, 1980; Molnar and Chen, 1983; Baranowski et al., 1984; Eyidogan and Jackson, 1985; Nelson et al., 1987; Abers et al., 1988; Chen, 1988; Fan and Ni, 1989; Molnar and Lyon-Caen, 1989; Chen and Molnar, 1990; Holt et al., 1991; Burtman and Molnar, 1993; Fan et al., 1994; Cotton et al., 1996; Ghose et al., 1997, 1998; Berberian et al., 2000; Bernard et al., 2000; Jackson et al., 2002; Chen and Yang, 2004; Bayasgalan et al., 2005; Mitra et al., 2005; Sloan et al., 2011; Craig et al., 2012; Ainscoe et al., 2017]. Active faults, according to known fault databases, 
Figure 1 (previous page): are represented by black lines [Taylor and Yin, 2009; Styron et al., 2010]. The depths of foreland and intermontane basins are plotted in kilometres [Chatterjee, 1971; Lee, 1985; Khaimov, 1986; Carroll et al., 1990; Graham et al., 1990; Nishidai and Berry, 1990; Allen et al., 1993; Cobbold et al., 1993; Royden, 1993; Allen et al., 1994; Huafu et al., 1994; Hendrix et al., 1992; Coutand et al., 2002; DeBatist et al., 2002; Yang and Liu, 2002; Bilham et al., 2003; Hetényi et al., 2006; Sobel et al., 2006; Zhou et al., 2006; Fang et al., 2007; Xuezhong et al., 2008; Yin et al., 2008; Bian et al., 2010; Goode et al., 2011; Mitra et al., 2011; Srinagesh et al., 2011; Kober et al., 2013; Li et al., 2013; Wei et al., 2013; Zhao et al., 2013; Macaulay et al., 2016; Bande et al., 2017; Bosboom et al., 2017; Brunet et al., 2017; Pei et al., 2017; Voigt et al., 2017; Yu et al., 2017; Kufner et al., 2018; Chapman et al., 2019; Morin et al., 2019]. Major cities have been plotted according to their population size [Cox, 2019]. Solid, grey lines mark out the national borders with countries labelled in capitals. Six were abbreviated as follows: $\mathrm{BA}=$ Bangladesh, $\mathrm{KY}=$ Kyrgyzstan, $\mathrm{MY}=$ Myanmar, $\mathrm{TA}=$ Tajikistan, $\mathrm{TU}=$ Turkmenistan and $\mathrm{UZ}=$ Uzbekistan. The inset map shows the population density of Central Asia [CIESIN, 2016]. An orthographic projection outlines the geographical extents of the main figure. 


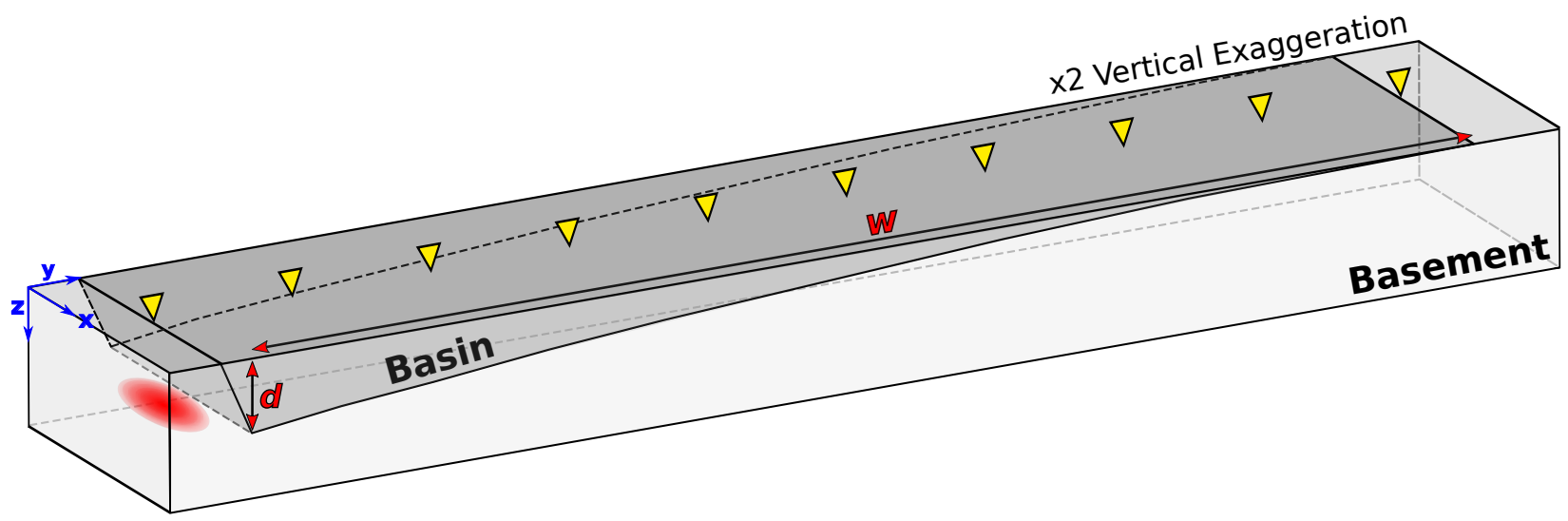

Figure 2: Schematic setup of the model used in this study. The model represents a simplified cross-section of a foreland-basin system orientated perpendicular to the range front. The model comprises two homogeneous mediums representing crystalline-basement rocks and foreland-basin sediments. The material properties for the basement rocks and foreland sediments are outlined in Section 2.1. The red shaded area, down-dip of the foreland basin represents a circular thrust rupture, with a diameter of $10 \mathrm{~km}$ and is planar in cross-section. Basin depth (d), basin width (w), fault dip and the distance between the fault source and the basin were varied to determine the effect that each variable had on the ground motion. The yellow triangles represent a selection of the modelled receiver stations that were aligned with the along-strike centre of the fault plane at kilometre intervals across the computational domain ( $\mathrm{Y}$ direction). 

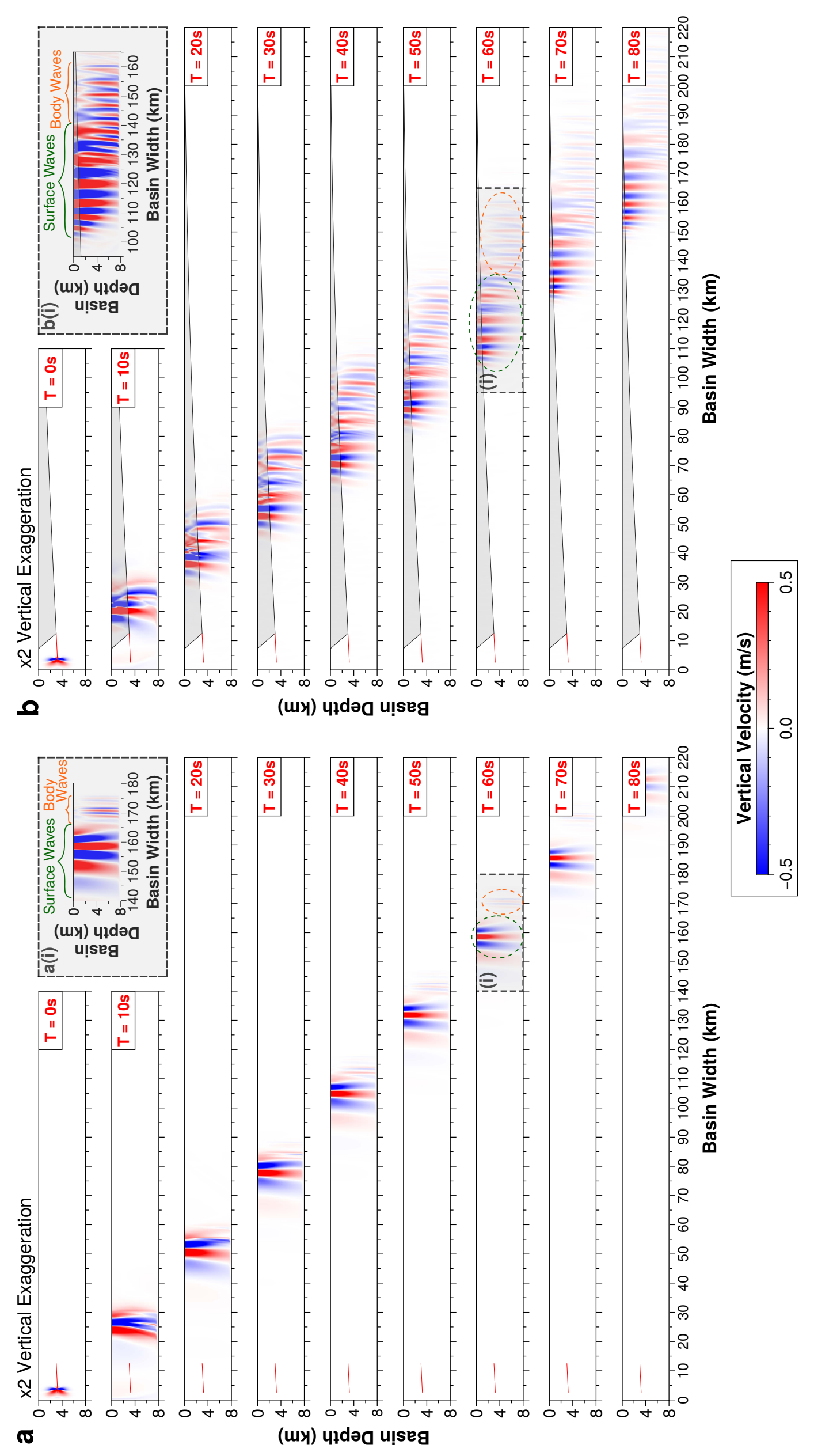

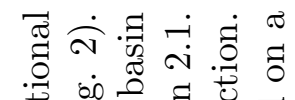

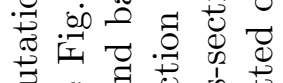

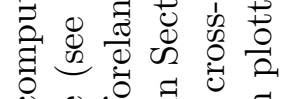
○ 远

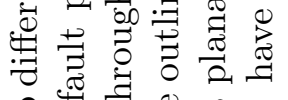

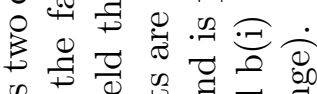

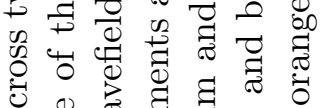

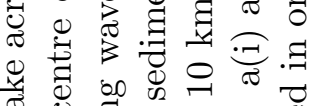

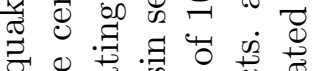
焉产

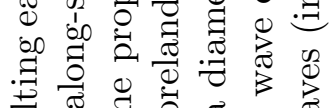

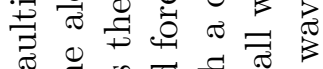

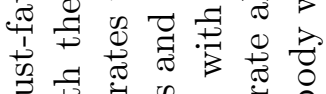

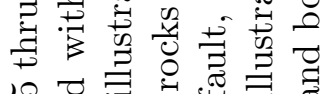

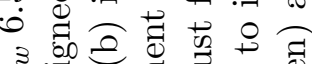
క $\approx$ \&

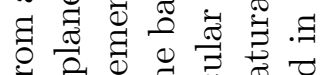

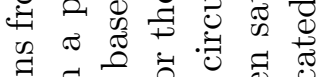

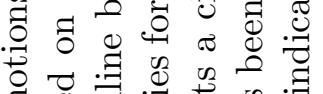

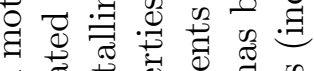

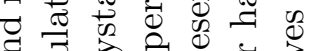

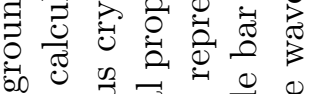
苨. 焉 चु ए व द्व च b0

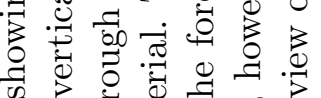

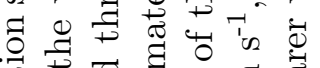
: 类

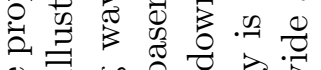

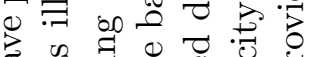

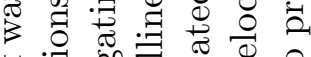
पे 0

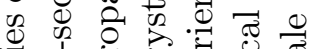
论 ठ

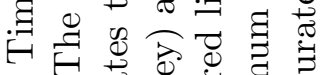
बिं ๖.

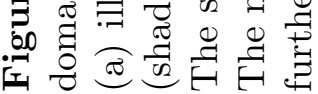




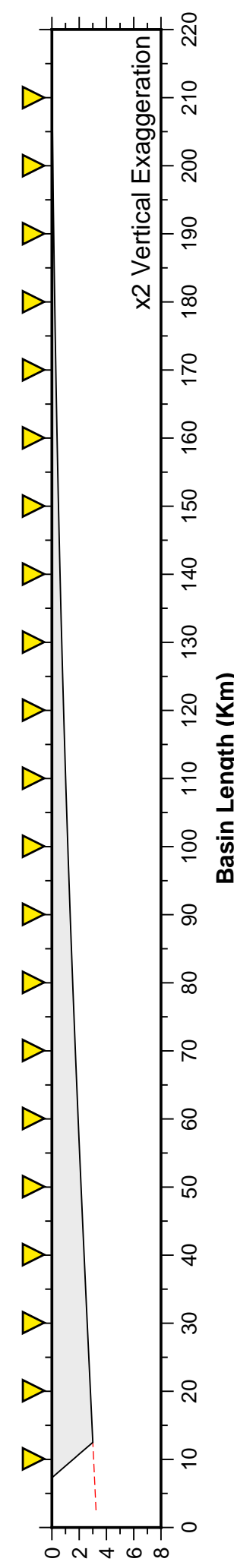

(ய)્ર) पıdəa u!seg

$\boldsymbol{\sigma}$
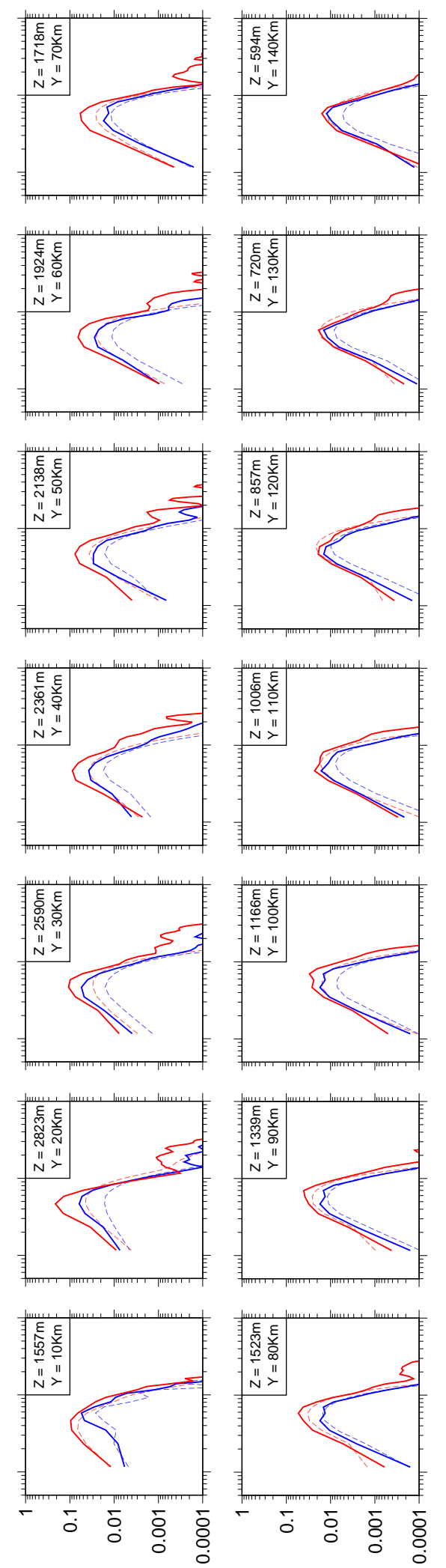

(u) әpnł!!dur $\forall$ aSd
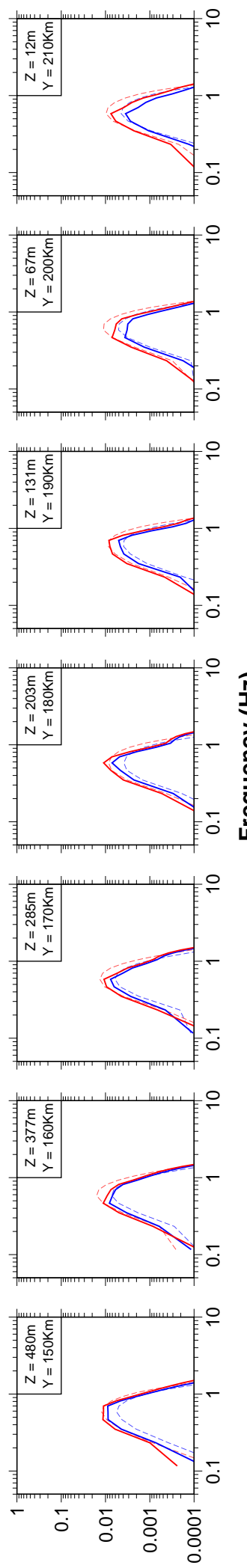

.

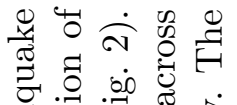

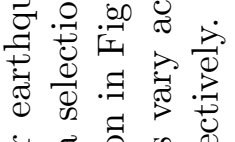

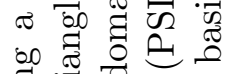

娄㱐

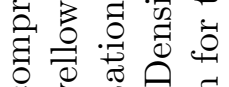

政䨪

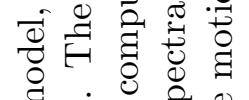

a $\dot{\vec{D}} \dot{0}$

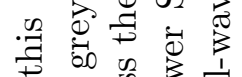

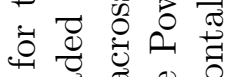

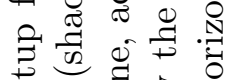

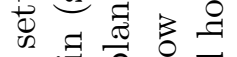

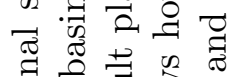

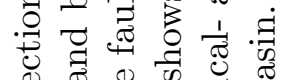

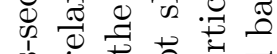

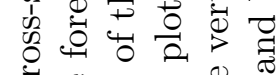

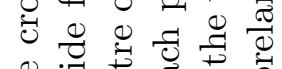

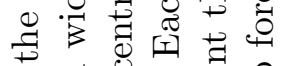
y

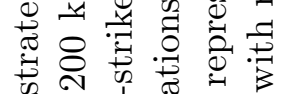

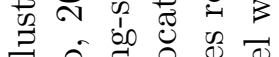

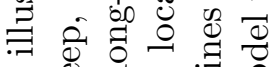
๘㐘 ๔ $₫$

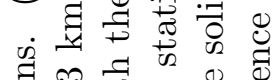

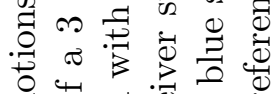

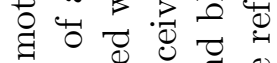
ఫ

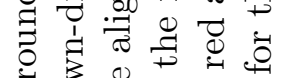

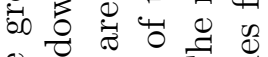
ఫ啳 车

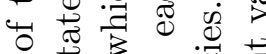

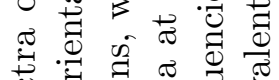

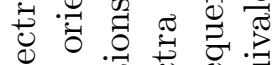

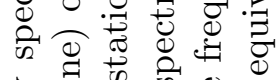

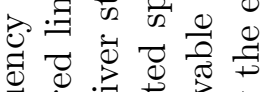
要

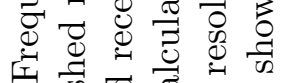
舟

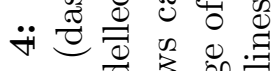

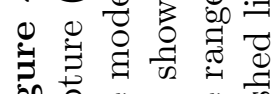
䖤 

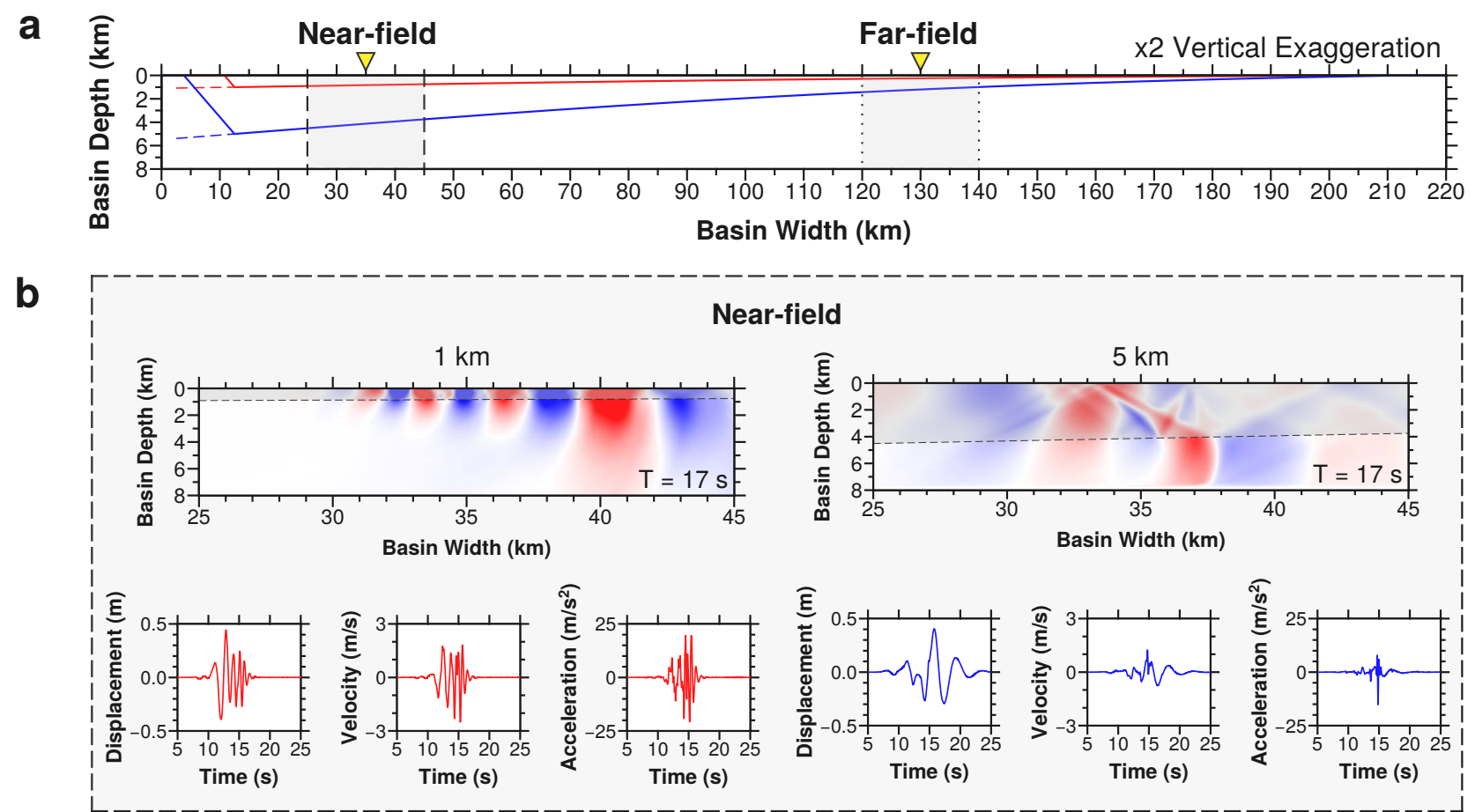

C

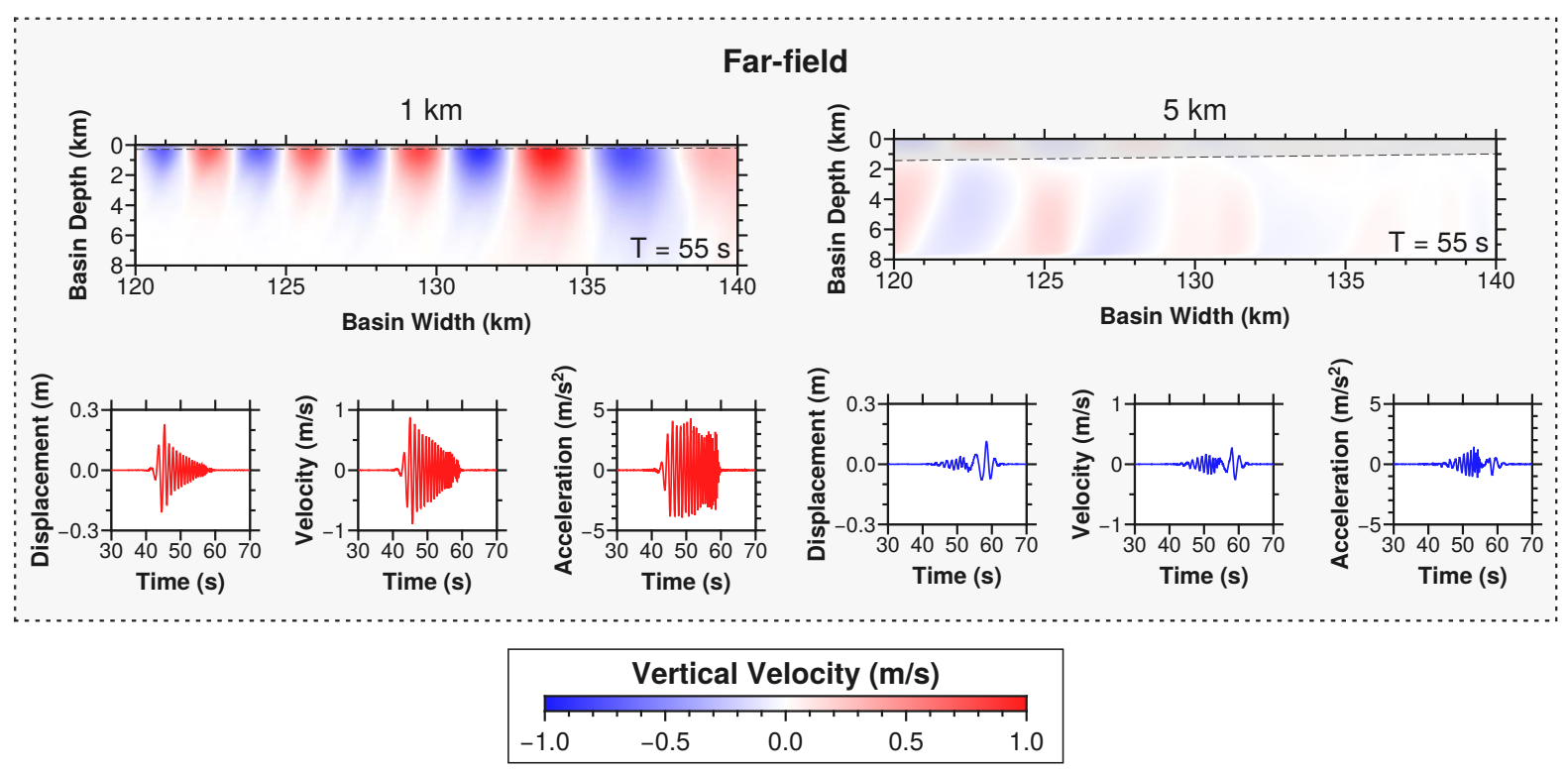

Figure 5: Calculated vertical velocities showing the near- and far-field effects of basin depth. (a) demonstrates the cross-sectional setup for two model simulations of varying basin depths; a $1 \mathrm{~km}$ deep basin denoted by a red line and a $5 \mathrm{~km}$ deep basin represented by a blue line. A $10 \mathrm{~km}$ planar fault is orientated down-dip of each foreland basin and illustrated as a dashed line. The shaded grey boxes outlined by dashes and dots represent the location of the near- (b) and far-field (c) results respectively, with waveforms shown at the yellow triangles, which represent receiver stations. (b) illustrates the resultant wavefield calculated for both the shallow $(1 \mathrm{~km})$ and deep $(5 \mathrm{~km})$ basins at a particular distance and time $(35 \mathrm{~km} / 17 \mathrm{~s})$ in the near-field. (c) illustrates the resultant wavefield calculated for both the shallow $(1 \mathrm{~km})$ and deep $(5 \mathrm{~km})$ basins at a particular distance and time $(130 \mathrm{~km} / 55 \mathrm{~s})$ in the far-field. The maximum vertical velocity for (b) and (c) is $\approx 3 \mathrm{~m} \mathrm{~s}^{-1}$, however, the scale bar has been saturated to illustrate all wave effects. 

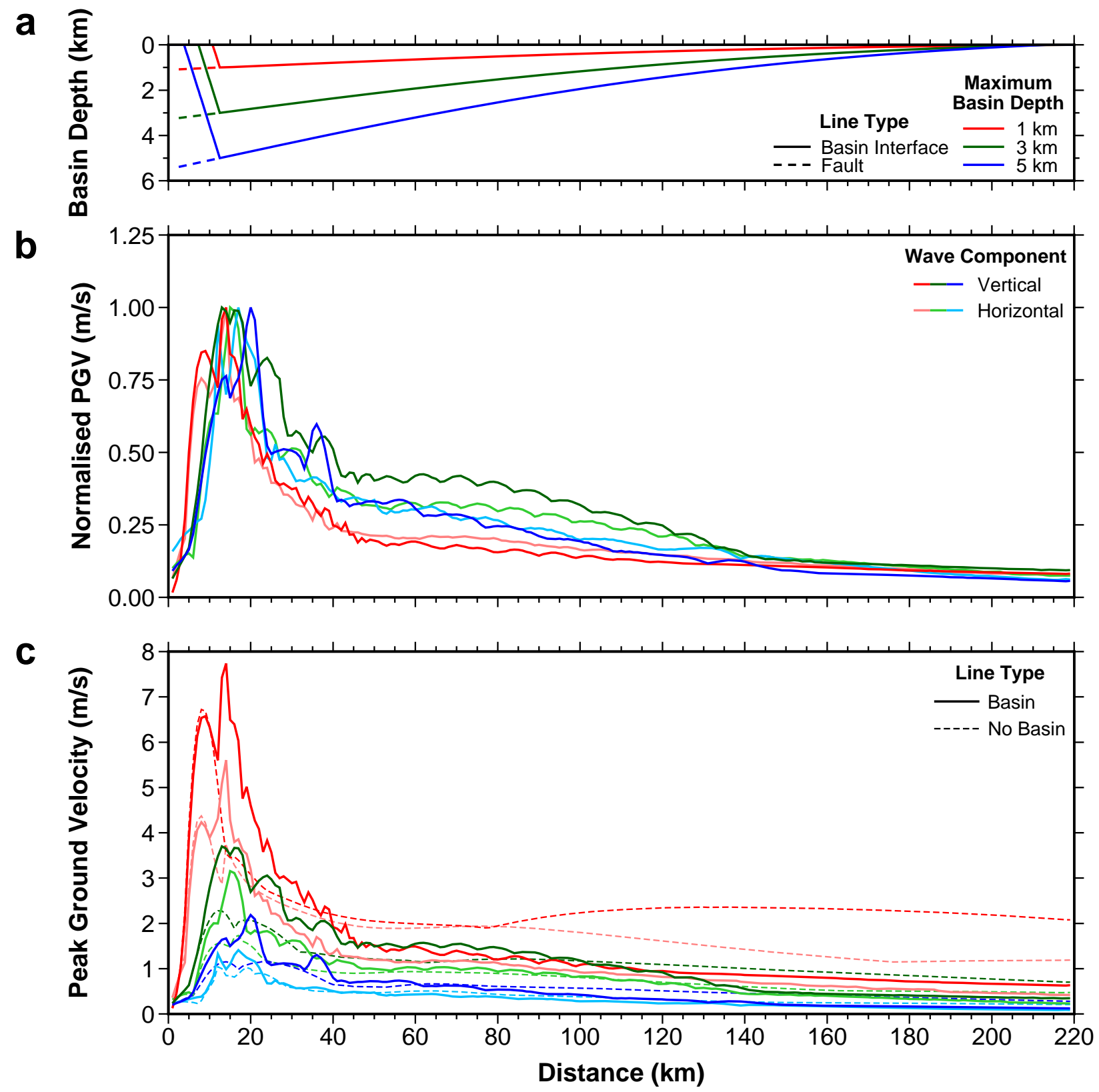

Figure 6: Peak ground velocity plotted as a function of distance across a foreland basin for three different basin depths. The basin-basement interface in (a) and resultant PGV in (b) and (c) for $1 \mathrm{~km}$, $3 \mathrm{~km}$ and $5 \mathrm{~km}$ deep basins are denoted by red, green and blue solid lines respectively. The vertical and horizontal components for each basin in (b) and (c) are illustrated by dark- and light-coloured lines respectively. (a) demonstrates the cross-sectional setup for model simulations of varying basin depths. A $10 \mathrm{~km}$ planar earthquake rupture is orientated down-dip of each foreland basin and is illustrated by a dashed line. (b) shows PGV as a function of distance plotted for different basin depths, normalised by the maximum value of PGV. (c) shows PGV plotted as a function of distance for a range of source depths. The dashed lines show the equivalent values for the reference models with no foreland basin. 

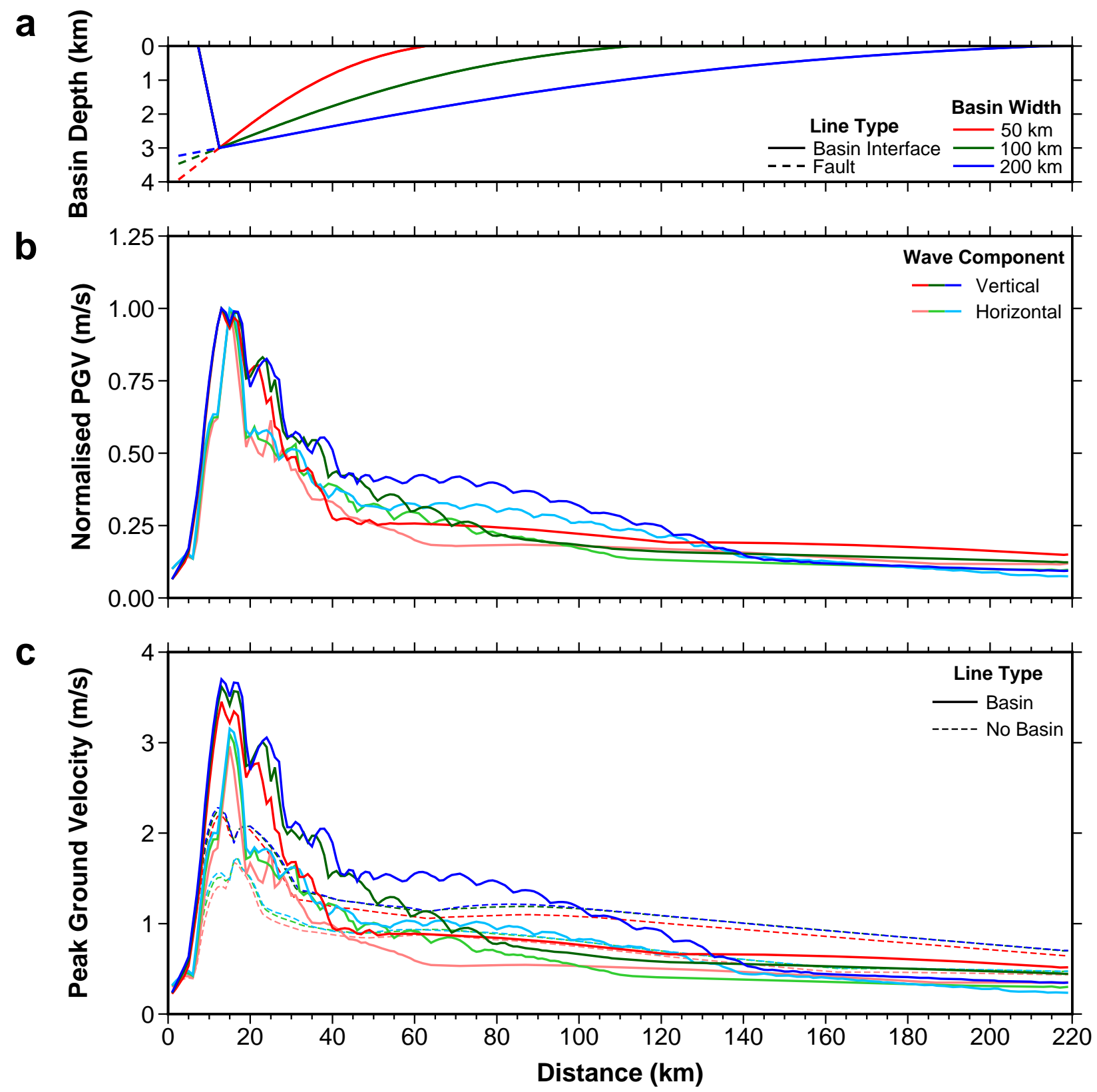

Figure 7: Peak ground velocity plotted as a function of distance across a foreland basin for three different basin widths. The basin-basement interface in (a) and resultant PGV in (b) and (c) for $50 \mathrm{~km}, 100 \mathrm{~km}$ and $200 \mathrm{~km}$ wide basins are denoted by red, green and blue solid lines respectively. The vertical and horizontal components of ground motion for each basin in (b) and (c) are illustrated by dark- and light-coloured lines respectively. (a) demonstrates the cross-sectional setup for model simulations of varying basin widths. A $10 \mathrm{~km}$ planar earthquake rupture is orientated down-dip of each foreland basin and is illustrated by a dashed line. (b) shows PGV as a function of distance plotted for different basin widths, normalised by the maximum value of PGV. (c) shows PGV plotted as a function of distance for a range of basin widths. The dashed lines show the equivalent values for the reference models with no foreland basin. 

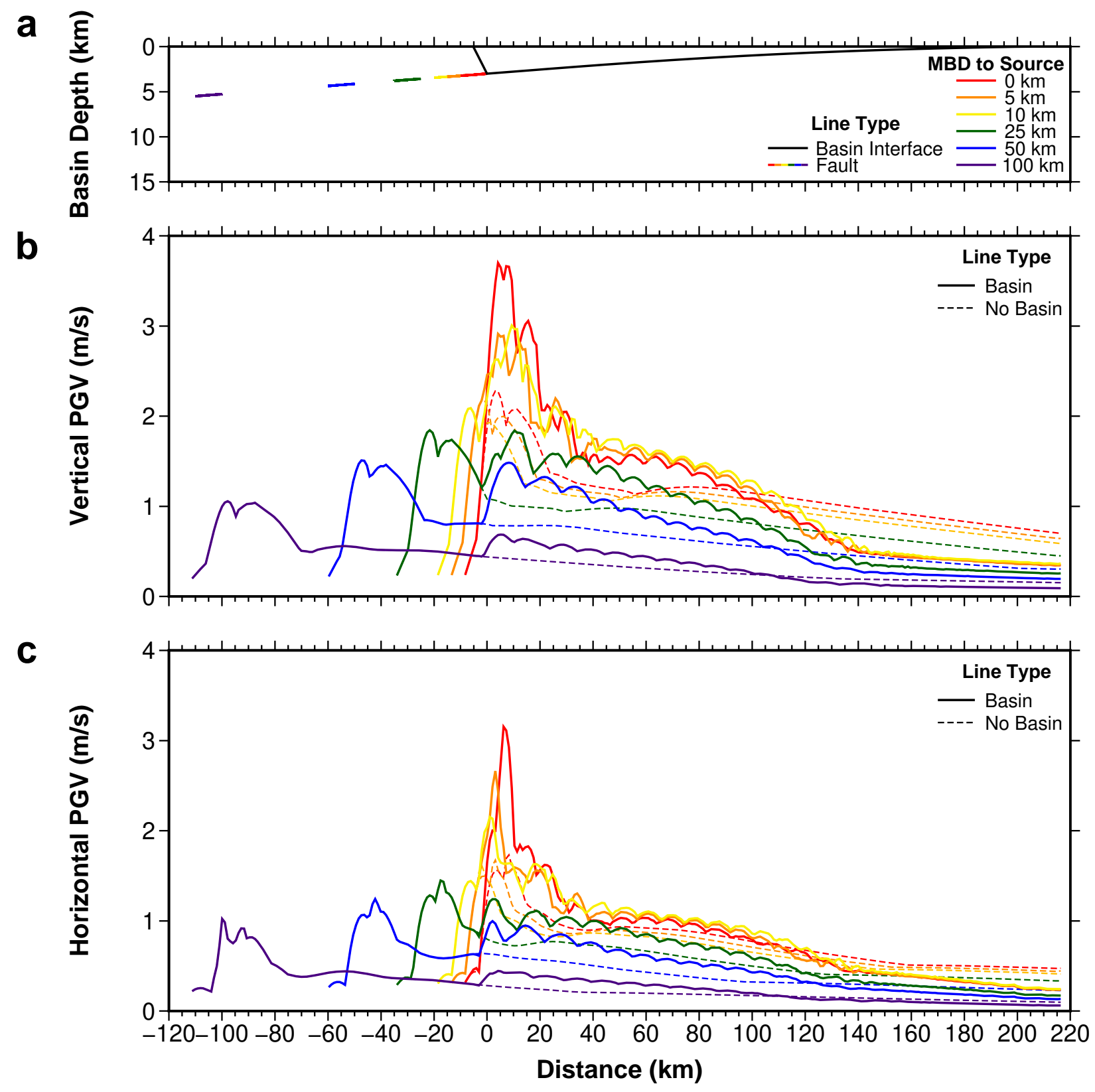

Figure 8: Peak ground velocity plotted as a function of distance across a foreland basin for six faults with different basin-to-source distances. Each fault is illustrated in (a), (b) and (c) by red, orange, yellow, green, blue and indigo coloured lines for basin-to-source distances of $0 \mathrm{~km}, 5 \mathrm{~km}, 10 \mathrm{~km}$, $25 \mathrm{~km}, 50 \mathrm{~km}$ and $100 \mathrm{~km}$ respectively. The dashed lines in (b) and (c) show the equivalent values for the reference models with no foreland basin. (a) demonstrates the cross-sectional setup for model simulations of varying distances between the Maximum Basin Depth (MBD) and sources. A $10 \mathrm{~km}$ planar earthquake rupture is orientated down-dip and positioned at various distances from a $3 \mathrm{~km}$ deep, $200 \mathrm{~km}$ wide foreland basin which is outlined in black. (b) shows vertical PGV plotted as a function of distance for a range of faults with varying basin-to-source distances. (c) shows horizontal PGV plotted as a function of distance for a range of faults with varying basin-to-source distances. 


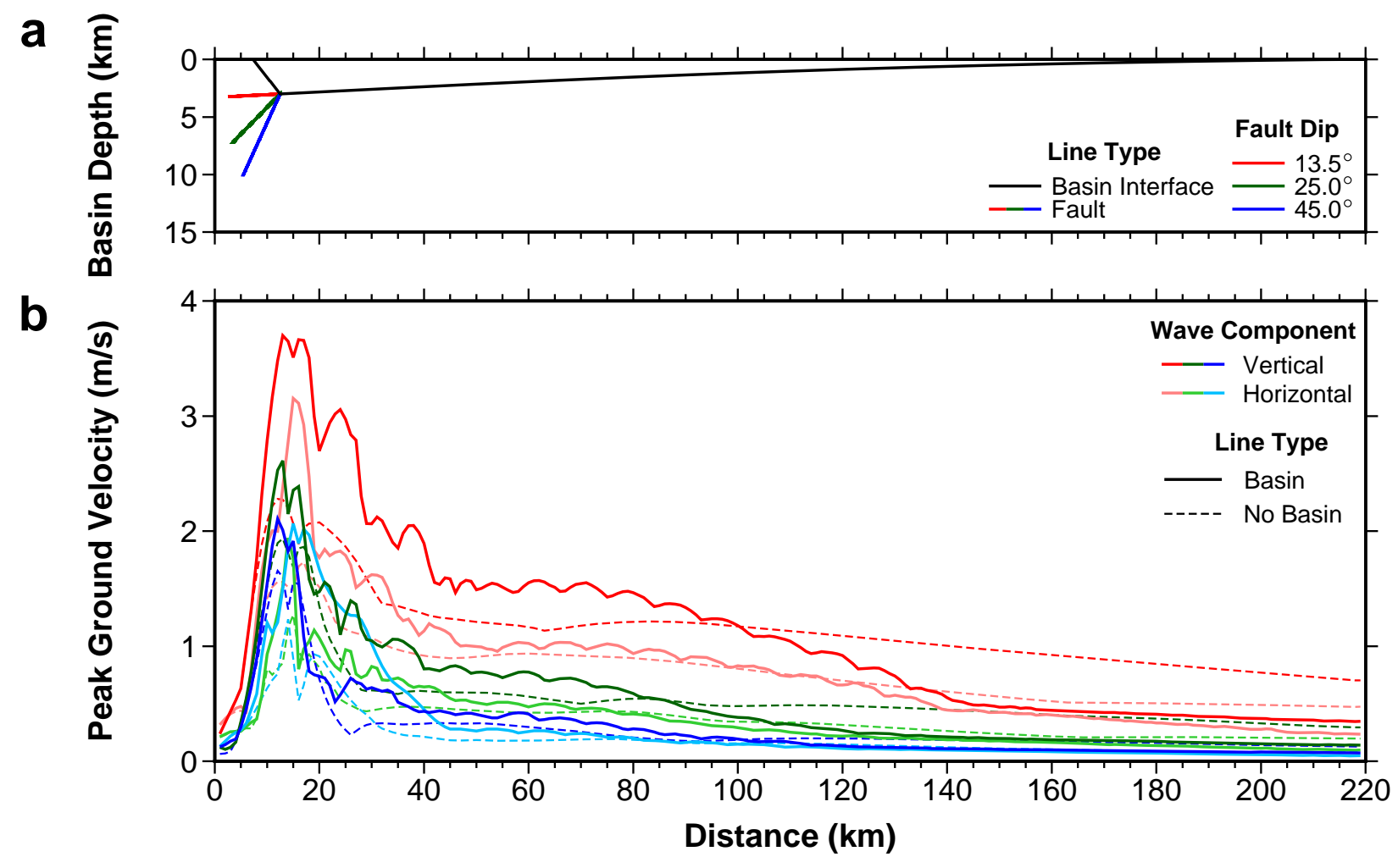

Figure 9: Peak ground velocity plotted as a function of distance across a foreland basin for three faults with different dips. Each fault is illustrated in (a) and (b) by red, green and blue lines for dips of $13.5^{\circ}, 25.0^{\circ}$ and $45.0^{\circ}$ respectively. (a) demonstrates the cross-sectional setup for model simulations of varying fault dips. A $10 \mathrm{~km}$ planar earthquake rupture is orientated at different angles, down-dip of a $3 \mathrm{~km}$ deep, $200 \mathrm{~km}$ wide foreland basin which is outlined in black. (b) shows PGV plotted as a function of distance for a range of source dips. The vertical and horizontal components are illustrated by dark- and light-coloured lines respectively. The dashed lines show the equivalent values for the reference models with no foreland basin. 

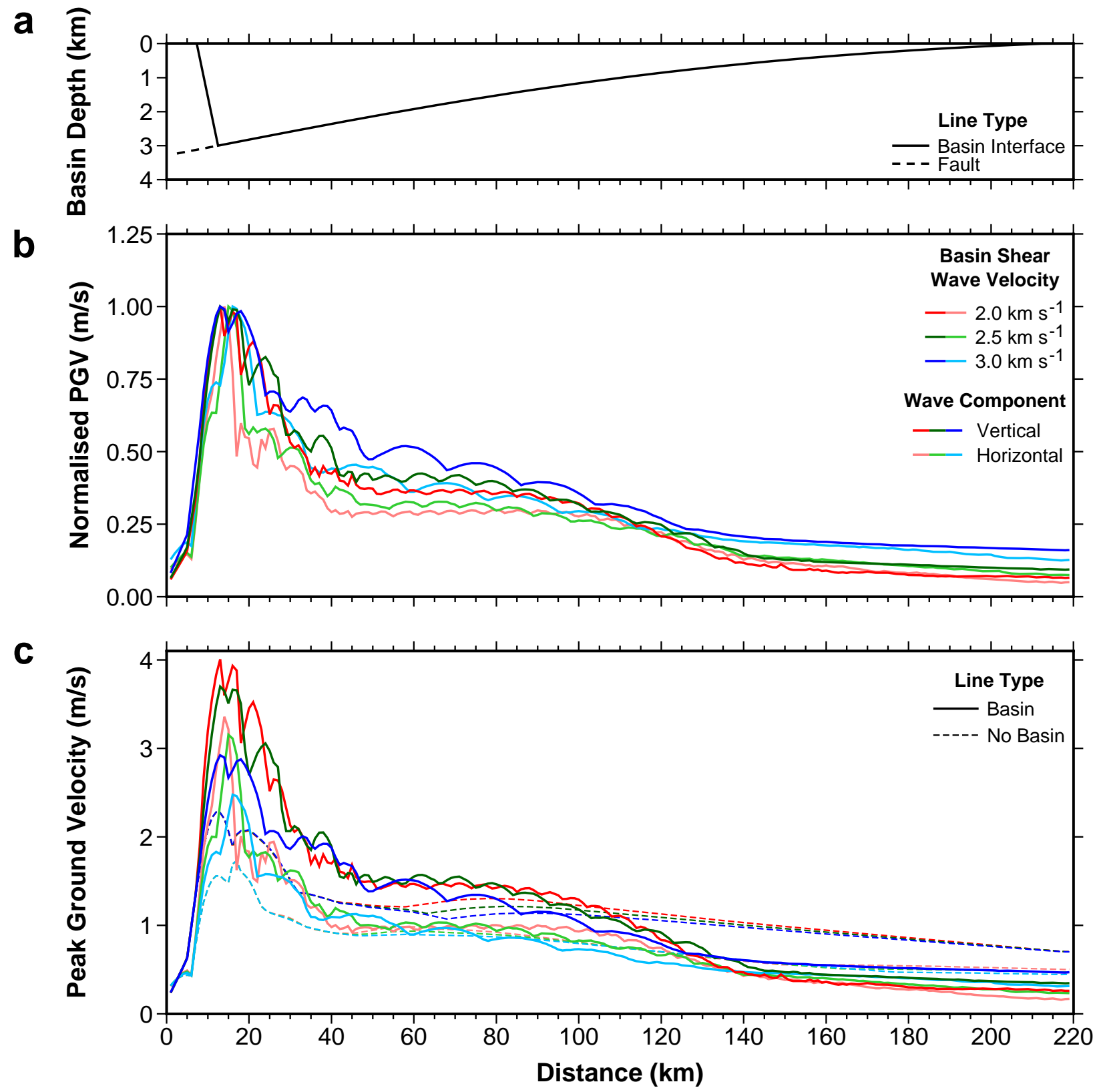

Figure 10: Peak ground velocity plotted as a function of distance across a foreland basin for three different basin shear-wave velocities (with the $\mathrm{P}$-wave velocity also varied to keep a constant $V_{P} / V_{S}$ ratio of 1.75). The resultant PGVs in (b) and (c) for shear-wave speeds of $2.0 \mathrm{~km} \mathrm{~s}^{-1}, 2.5 \mathrm{~km} \mathrm{~s}^{-1}$ and $3.0 \mathrm{~km} \mathrm{~s}^{-1}$ are denoted by red, green and blue lines respectively. The vertical and horizontal components in (b) and (c) are illustrated by dark- and light-coloured lines respectively. (a) demonstrates the cross-sectional setup for the model simulations, comprising a $10 \mathrm{~km}$ planar earthquake rupture (dashed black line) orientated down-dip of a $3 \mathrm{~km}$ deep, $200 \mathrm{~km}$ wide foreland basin (solid black line). (b) shows PGV as a function of distance plotted for different basin S-wave velocities, normalised by the maximum value of PGV. (c) shows PGV plotted as a function of distance for a range of basin S-wave velocities. The dashed lines show the equivalent values for the reference models with no foreland basin. 
a

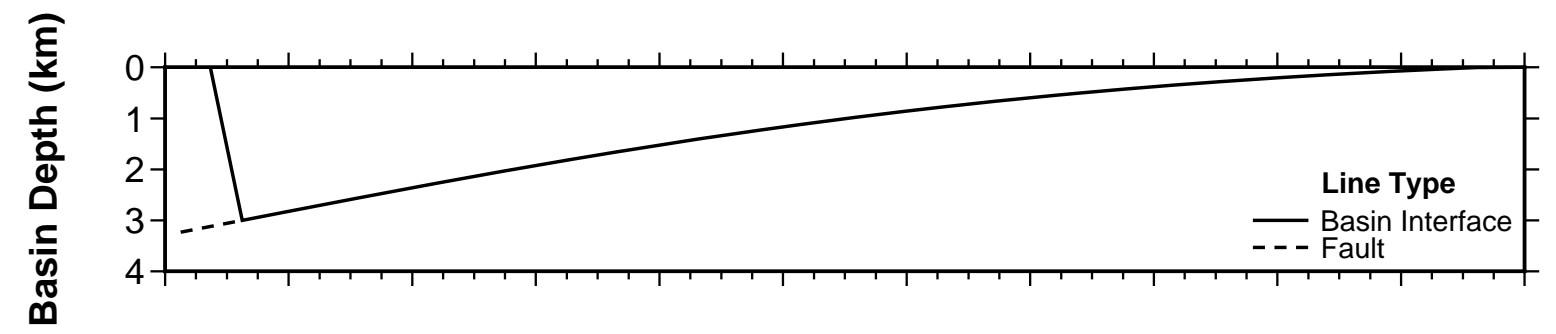

b

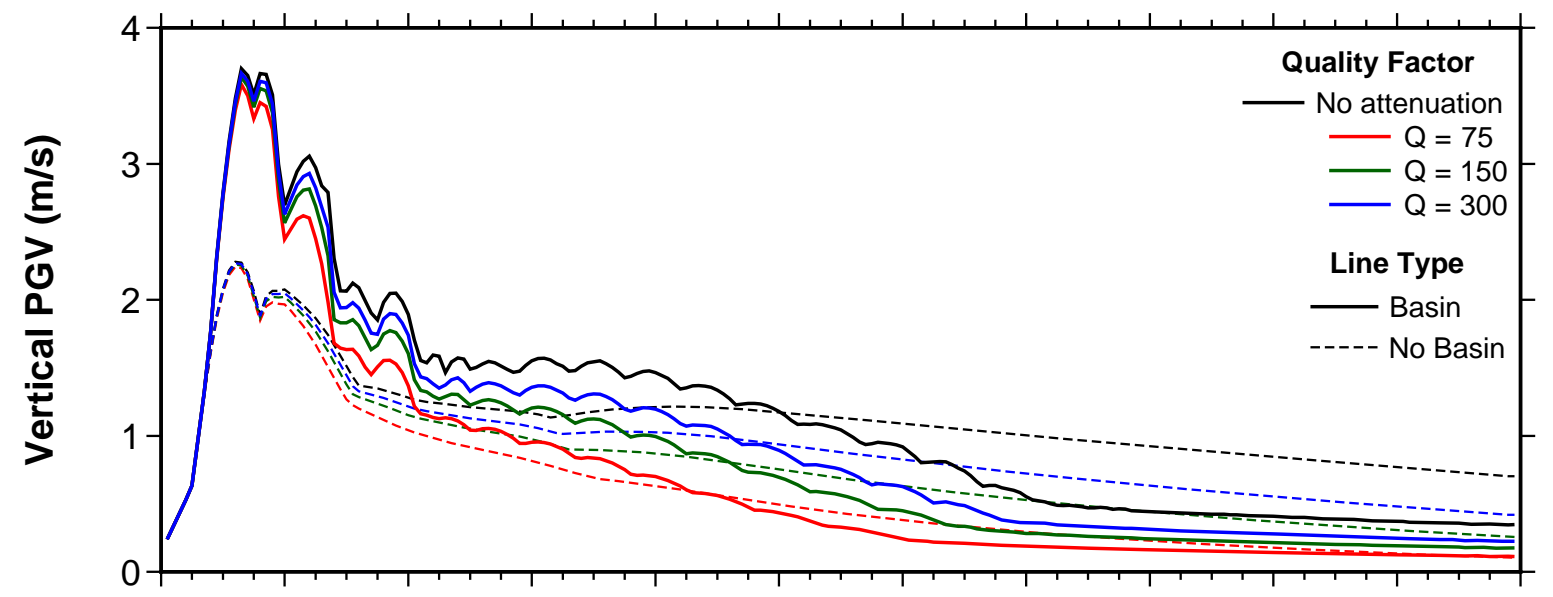

C

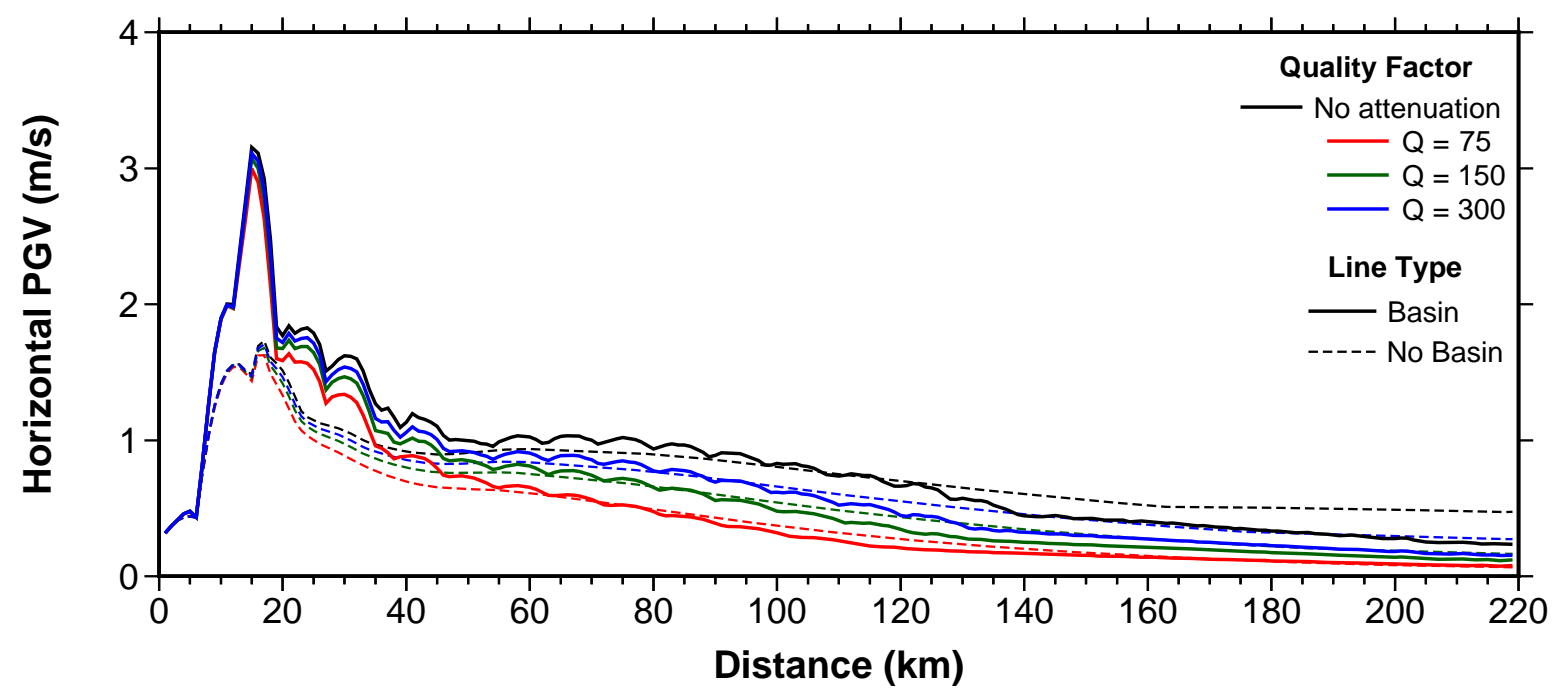

Figure 11: Peak ground velocity plotted as a function of distance across a foreland basin for four simulations with different levels of attenuation. The resultant velocities in (b) and (c) for quality factors of 75, 150 and 300, in addition to the model simulation that was run under elastic conditions (labelled 'No attenuation') are denoted by red, green, blue and black lines respectively. The dashed lines in (b) and (c) show the equivalent values for the reference models with no foreland basin. (a) demonstrates the cross-sectional setup for the model simulations, comprising a $10 \mathrm{~km}$ planar earthquake rupture (black dashed line) orientated down-dip of a $3 \mathrm{~km}$ deep, $200 \mathrm{~km}$ wide foreland basin (black solid line). (b) shows vertical PGV plotted as a function of distance for a range of attenuation quality factors. (c) shows horizontal PGV plotted as a function of distance for a range of attenuation quality factors. 


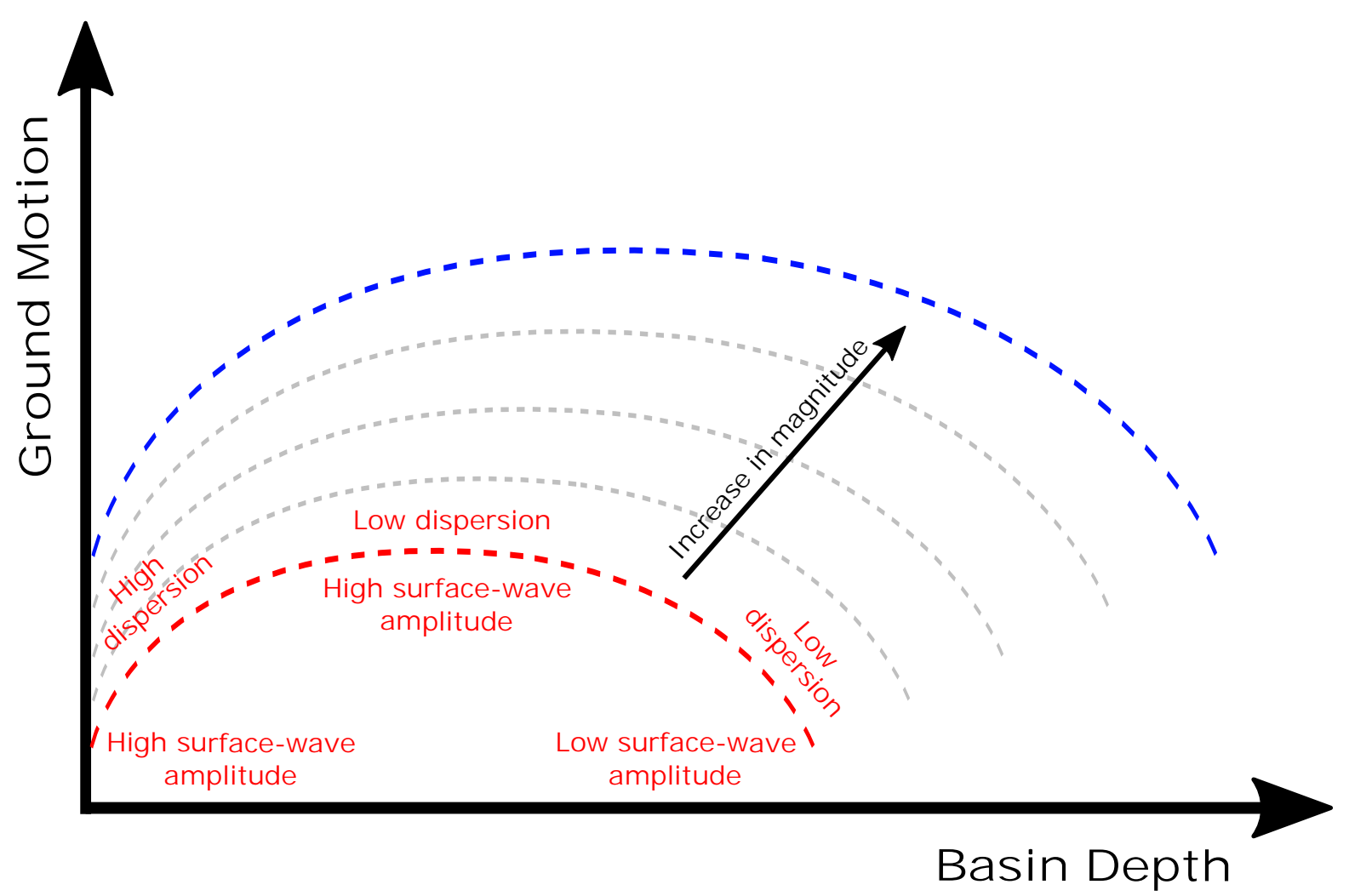

Figure 12: Schematic diagram illustrating the effect of basin depth on ground motion for a location near the centre of the basin. The red dashed line denotes the ground motion trend produced by our modelled $M_{w} 6.5$ thrust-faulting earthquake, whilst the blue and grey dashed lines are the expected trends if the source magnitude was increased. 
a

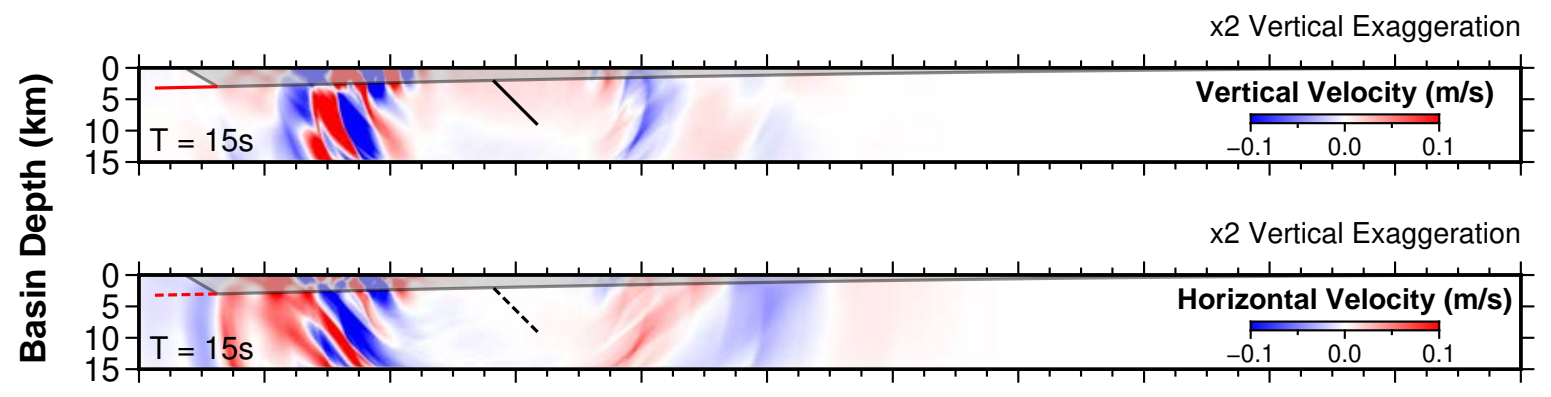

b

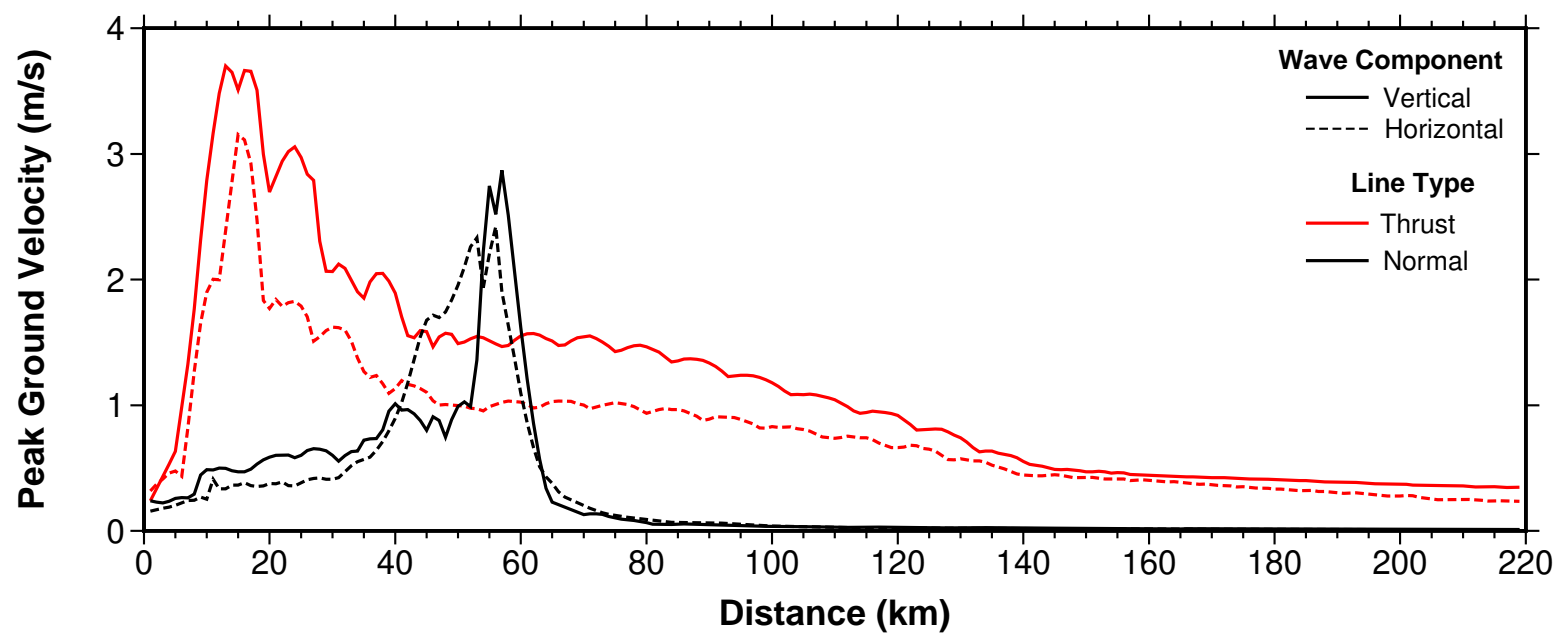

Figure 13: Calculated velocities plotted as a function of distance across a foreland basin for two $\mathrm{M}_{w} 6.5$ ruptures with different earthquake mechanisms. (a) demonstrates the cross-sectional setup for a normal-faulting earthquake in the underlying basement, overlain with the resultant vertical and horizontal wavefield produced at 15 seconds from the onset of the earthquake rupture. The maximum velocity is $\approx 3 \mathrm{~m} \mathrm{~s}^{-1}$, however, the scale bar has been saturated to illustrate all wave effects. (b) shows PGV plotted as a function of distance for a normal-faulting earthquake simulation (black line). For comparison, we have plotted the PGV for a range-front thrust-faulting earthquake (red line) using the same basin geometry. The vertical and horizontal components are illustrated by solid and dashed lines respectively. 